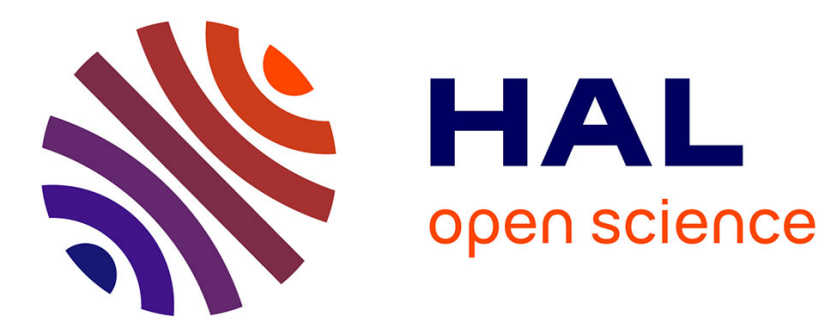

\title{
Recent advances in the synthesis of tetrahydrofurans and applications in total synthesis
}

Aurélien de La Torre, Claire Cuyamendous, Valérie Bultel-Poncé, Thierry Durand, Jean-Marie Galano, Camille Oger

\section{- To cite this version:}

Aurélien de La Torre, Claire Cuyamendous, Valérie Bultel-Poncé, Thierry Durand, Jean-Marie Galano, et al.. Recent advances in the synthesis of tetrahydrofurans and applications in total synthesis. Tetrahedron, 2016, 72 (33), pp.5003-5025. 10.1016/j.tet.2016.06.076 . hal-02592332

\section{HAL Id: hal-02592332 \\ https://hal.science/hal-02592332}

Submitted on 26 May 2020

HAL is a multi-disciplinary open access archive for the deposit and dissemination of scientific research documents, whether they are published or not. The documents may come from teaching and research institutions in France or abroad, or from public or private research centers.
L'archive ouverte pluridisciplinaire HAL, est destinée au dépôt et à la diffusion de documents scientifiques de niveau recherche, publiés ou non, émanant des établissements d'enseignement et de recherche français ou étrangers, des laboratoires publics ou privés. 


\title{
Recent advances in the synthesis of tetrahydrofurans and applications in total synthesis
}

\author{
Aurélien de la Torre, Claire Cuyamendous, Valérie Bultel-Poncé, Thierry Durand, \\ Jean-Marie Galano*, Camille Oger*
}

Institut des Biomolécules Max Mousseron, UMR 5247 CNRS, Université de Montpellier, ENSCM, Faculté de Pharmacie de Montpellier, 15 Avenue Charles Flahault, Bâtiment D, 34093 Montpellier Cedex 05, France

\section{Keywords:}

Tetrahydrofurans

Stereoselective synthesis

THF-containing molecules

Total synthesis

\section{Contents}

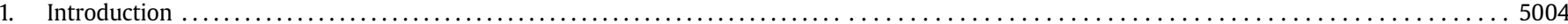

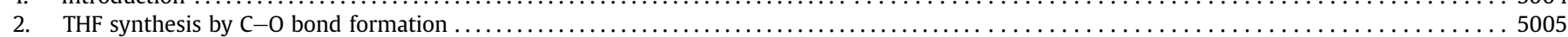

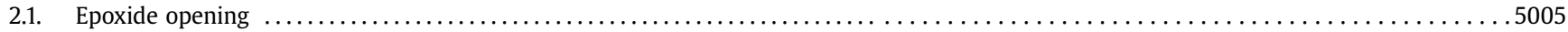

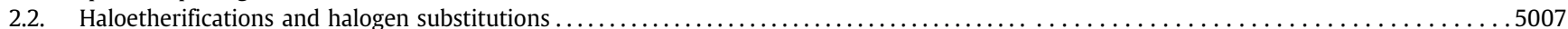

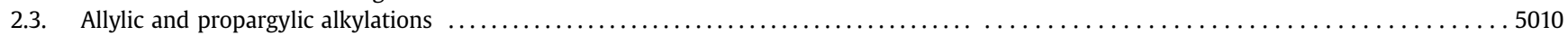

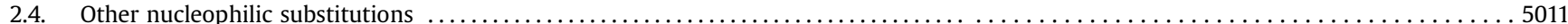

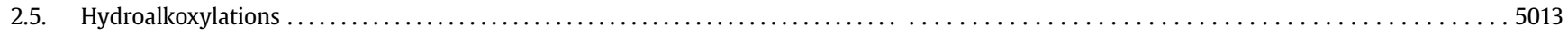

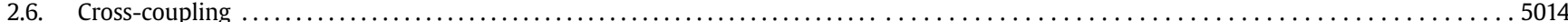

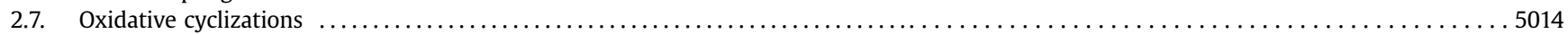

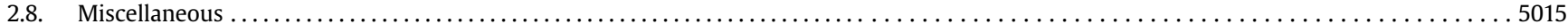

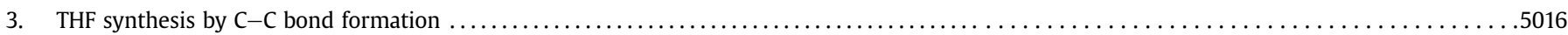

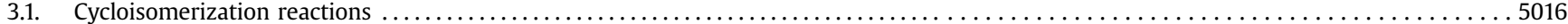

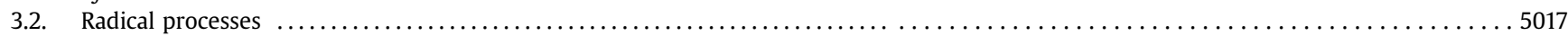

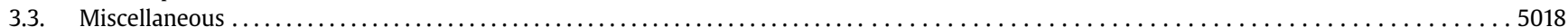

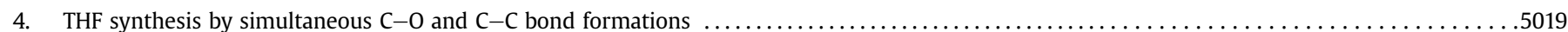

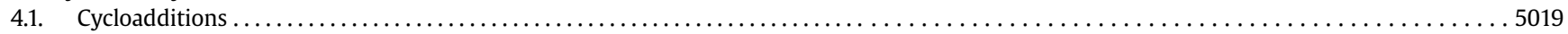

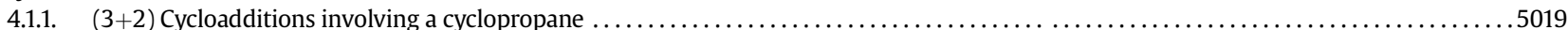

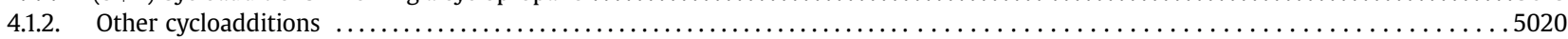

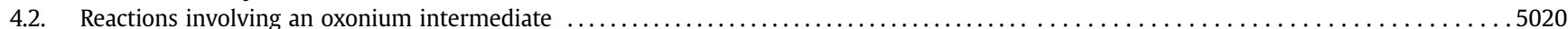

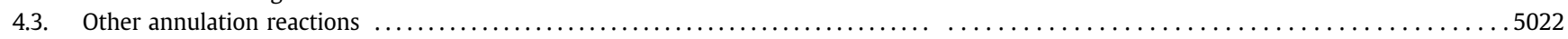

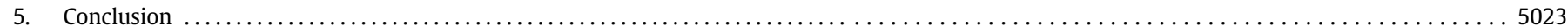

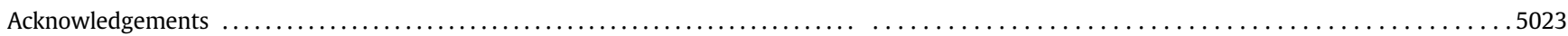

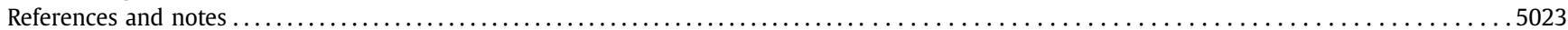

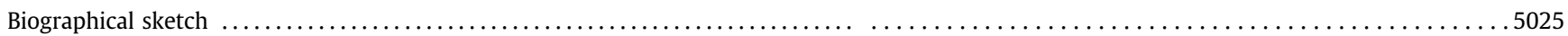

* Corresponding authors. E-mail addresses: jean-marie.galano@umontpellier.fr (J.-M. Galano), camille.oger@umontpellier.fr (C. Oger). 


\section{List of acronyms}

ACDC asymmetric counteranion-directed catalysis

AIBN azobisisobutyronitrile

CAN cerium ammonium nitrate

CBS Corey-Bakshi-Shibata

COD cyclooctadiene

Cp cyclopentadienyl

CSA camphorsulfonic acid

DCE dichloroethane

DCM dichloromethane

DFT density functional theory

DIPA diisopropylamine

DIPEA diisopropylethylamine

DME dimethylether

DPE 2-(diphenylphoshinoyl)ethylidene

esp $\quad \alpha, \alpha, \alpha^{\prime}, \alpha^{\prime}$-tetramethyl-1,3-benzenediproponoate

EWG electron withdrawing

HAT hydrogen atom transfer

LA Lewis acid

MOM methoxymethyl

$\begin{array}{ll}\text { NBS } & N \text {-bromosuccinimide } \\ \text { nmp } & N \text {-methyl-2-pyrrolidone } \\ \text { Nu } & \text { nucleophile } \\ \text { PIDA } & \text { phenyliodine(III) diacetate } \\ \text { PMB } & \text { para-methoxybenzyl } \\ \text { PMP } & \text { para-methoxyphenyl } \\ \text { PPTS } & \text { pyridinium para-toluenesulfonate } \\ \text { PTSA } & \text { para-toluenesulfonic acid } \\ \text { PyBOX } & \text { pyridine bis(oxazoline) } \\ \text { SEM } & \text { [2-(trimethylsilyl)ethoxy]methyl acetal } \\ \text { TBAF } & \text { tetra } n \text {-butyl ammonium fluoride } \\ \text { TBAI } & \text { tetrabutyl ammonium iodide } \\ \text { TBCO } & \text { tetrabromocyclohexadienone } \\ \text { TBDPS } & \text { tert-butyldiphenylsilyl } \\ \text { TBHP } & \text { tert-butylhydroperoxide } \\ \text { TBS } & \text { tert-butyldimethylsilyl } \\ \text { THF } & \text { tetrahydrofuran } \\ \text { TIPS } & \text { triisopropylsilyl } \\ \text { TMS } & \text { trimethylsilyl } \\ \text { Ts } & \text { tosyl }\end{array}$

\section{Introduction}

Many natural products incorporate tetrahydrofuran (THF) moieties, including macrolides, ${ }^{1}$ polyether ionophores, ${ }^{2}$ acetogenins ${ }^{3}$ or oxidized lipids, ${ }^{4}$ with a wide array of bioactivities (Fig. 1). Those bioactive compounds contain cis or trans tetrahydrofurans, as well as substituents (one to four) on the ring. Natural products have been the mainstay of research in organic chemistry and encouraged the development of new synthetic methods. In this sense, the literature overflows with stereoselective synthetic procedures for obtaining substituted THF as well as polycyclic structures (e.g., spiro-structures). The copious quantity of literature reports in this area may confuse chemists that want to easily find the most appropriate method and the best conditions and/or substrates. In 2007, Wolfe and Hay provided an overview of the THF preparation processes. ${ }^{5}$ Since their work, further advances and improvements have been made and new methods were reported.

The present review intends to present the recent progress in the preparation of THF and THF-containing polycyclic structures since 2007. Above all, this review aims to give data for organic chemists

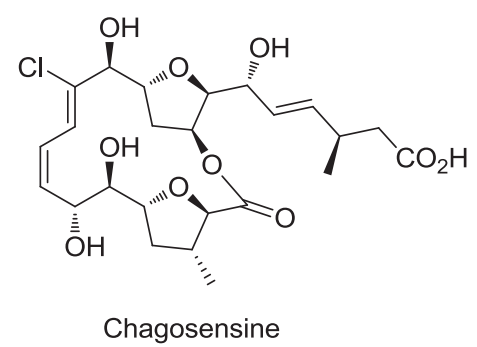

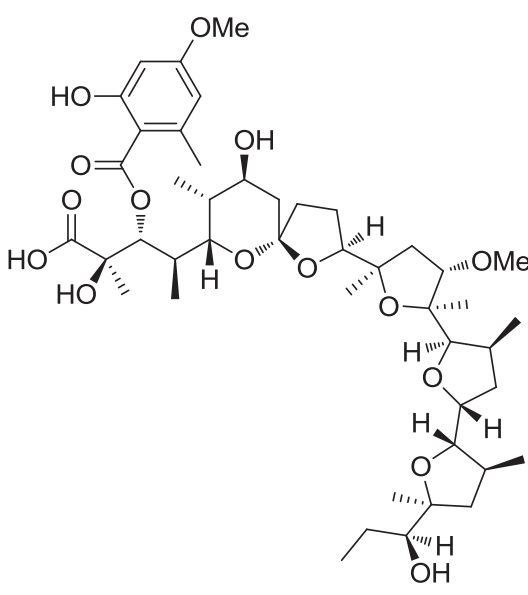<smiles>CCCCCCCCCC[C@@H](O)[C@H]1CC[C@H]([C@H]2CC[C@H]([C@H](O)CCCCCCCCCC[C@H](O)CC3=C[C@H](C)OC3=O)O2)O1</smiles><smiles>CCCCC[C@H](O)/C=C/[C@H]1O[C@H]([C@H](O)C/C=C/CCCCCC(=O)O)C[C@H]1O</smiles>

10-epi-17(R,S)-SC- $\Delta^{15}$-11-dihomo-IsoF

Cationomycin

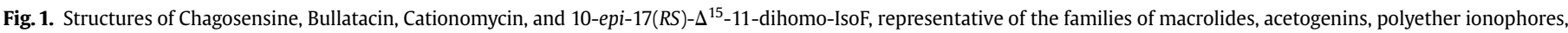
and oxidized lipids. 
involved in the synthesis of THF-containing natural products and answer questions about enantio-, diastereo-, and chemo-selectivities or functional group tolerance. The recent total/formal synthesis of bioactive molecules has been covered.

The manuscript is organized in three sections. The first one focuses on the preparation of THF through $\mathrm{C}-\mathrm{O}$ bonds formation. The second section concentrates on $\mathrm{C}-\mathrm{C}$ bond formation. The third section presents simultaneous $\mathrm{C}-\mathrm{O}$ and $\mathrm{C}-\mathrm{C}$ bond formation for the synthesis or preparation of THF.

In all these three sections, some mechanistic information is given. cis or trans relationship, enantio-, diastereo-, and chemoselectivities are highlighted. In addition, the application of methods for the synthesis of natural product is provided at the end of each section focusing on the description of the THF formation step. Information such as functional group tolerance, side reactions or different assays realized by the authors is also reported. Only the direct syntheses of THF will be presented herein, excluding methods that form lactones or lactols. Dihydrofurans and benzofurans were also put aside. For simplicity, the substitution pattern of the THF will be described using atom numbering around the cycle, starting with 1 on the oxygen (Fig. 2).<smiles>[R]C1OC(C)C([R])C1[R]</smiles>

Fig. 2. Atom numbering of the THF.

Although we tried to be as exhaustive as possible, as this area of organic chemistry is wide, we mostly wanted this review to be comprehensive and useful.

\section{THF synthesis by $\mathrm{C}-\mathrm{O}$ bond formation}

\subsection{Epoxide opening}

Nucleophile opening of epoxide(s) is a method of choice for the formation of tetrahydrofuran cycles. First described in 1978 by the group of Kishi, ${ }^{6}$ it remained highly used in the synthesis of THFcontaining compounds. One main advantage is that the epoxide can be easily prepared in an enantioselective fashion thanks to the methods developed by Sharpless, ${ }^{7}$ Jacobsen $^{8}$ or Shi. ${ }^{9}$

Recent advances in this field are mainly related to cascade epoxide opening. Indeed, since Cane-Celmer-Westley's mechanistic proposal for the biosynthesis of polyether ionophores, ${ }^{10}$ epoxide opening cascades have become increasingly studied in synthetic organic chemistry as an elegant way to access poly-THF structures. $^{11}$

For example, Marshall et al. reported a zinc-mediated cascade cyclization of a triepoxide, allowing the access to bis-THF in moderate to good yields (Scheme 1). ${ }^{12,13}$ This process allows control of all the stereocenters upstream set by Sharpless and Shi epoxidation reactions and was successfully applied to the synthesis of C17-C32 fragment of Ionomycin.
Another recent cascade epoxide opening was developed by Florence and Cadou. The reaction was initiated by the addition of an organolithium to an epoxide, activated by the Lewis acid $\mathrm{BF}_{3} \cdot \mathrm{Et}_{2} \mathrm{O}$. The residual lithium alkoxide triggers a cyclization onto a second epoxide, which permits the desymmetrization of the starting bisepoxide (Scheme 2). ${ }^{14}$ Once again, the stereochemical outcome of the reaction depends on the configuration of the starting oxiranes. Remarkably, this method allows the formation of bis-THF starting from tris-epoxides, in moderate to good yield depending on the nucleophile. A similar strategy has been reported by Veidenberg et al., with an amine as the nucleophile and catalyzed by $\mathrm{Co}^{\mathrm{II}}$ salen. ${ }^{15}$ This latest method is presented as both a desymmetrization and a racemic resolution. Although, the yield of this transformation is quite low and only water and Boc-amide are described as nucleophiles, the products are obtained in excellent enantio- and diastereo-selectivies. Under enzymatic catalysis conditions, the epoxide opening cascade can also be triggered by epoxide hydrolases, followed by a spontaneous cyclization without any cyclase, as described by Faber and co-workers in the desymmetrization of meso bis-epoxides. ${ }^{16}$ Finally, Hu et al. recently revealed that the cascade epoxide opening could also be triggered by the intramolecular attack of a hydroperoxide under basic conditions. ${ }^{17}$

Except for cascade reactions, recent advances in the field of THF synthesis by epoxide opening are scarce. Blanc and Toste recently developed a homoallylic alcohol resolution method, based on vanadium-catalyzed epoxidation followed by a cyclization induced by CSA (Scheme 3). ${ }^{18}$ This strategy allows easy access to enantioenriched oxolanes, in moderate yields since this process involves a resolution.

The epoxide opening reaction is largely used in total synthesis for the preparation of tetrahydrofuran units. It actually permits control of the stereogenic centers in advance thanks to asymmetric epoxidation reactions, and only needs acid or basic conditions, usually at room temperature, to induce the cyclization step. Thus, the literature is rich in acid catalyzed epoxide opening cyclizations, using either Brønsted acids such as PPTS ${ }^{19}$ or CSA, or Lewis acids as the standard $\mathrm{BF}_{3} \cdot \mathrm{Et}_{2} \mathrm{O}$. Nevertheless, some unusual acids were also studied, as well as basic media, and all these efforts will be presented herein.

CSA is one of the most common acids used in total synthesis. As an example, in the course of the synthesis of the C14-C22 fragment of Amphidinolides X and Y, Dai and co-workers described an efficient 5-endo-tet cyclization thanks to the activation of the epoxide by a vinyl group and CSA, starting from $-40^{\circ} \mathrm{C}$ to room temperature (Scheme 4). ${ }^{20}$

In another example, Morimoto et al. ${ }^{21}$ used only CSA in dichloromethane, at room temperature, to perform cyclization in cascades, from one tertiary hydroxyl group onto a bis-epoxide, to produce two new tetrahydrofurans (Scheme 5).

Similar strategies were employed by several organic chemists for the total synthesis of Synparvolide $C,{ }^{22}$ Heronapyrrole $C,{ }^{23}$ Heronapyrrole $\mathrm{D},{ }^{24}$ and the fragments of the (-)-Lytophilippine A. ${ }^{25}$

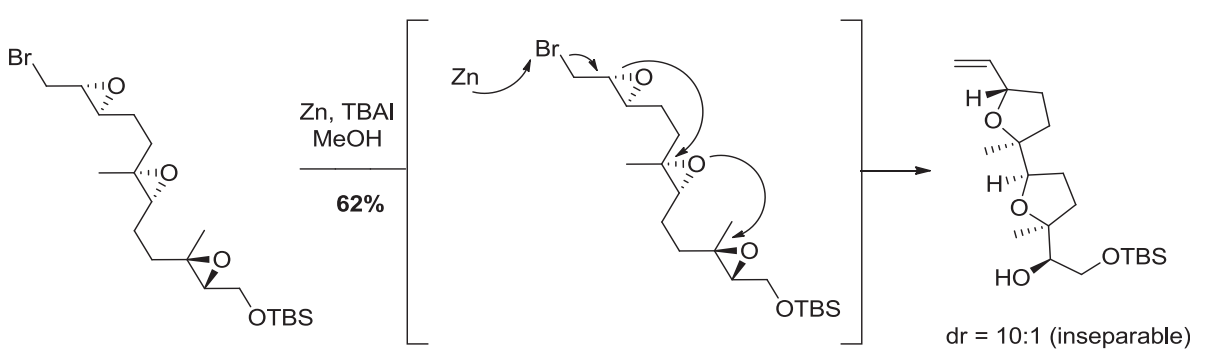

Scheme 1. Zn-mediated cascade epoxide opening. 


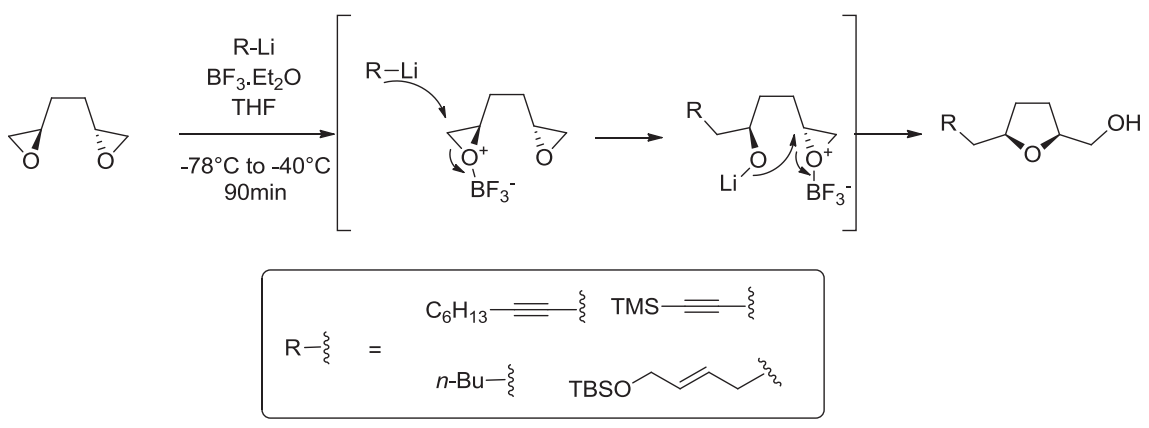

Scheme 2. Bis-epoxide desymmetrization by addition of an organolithium and cascade cyclization.

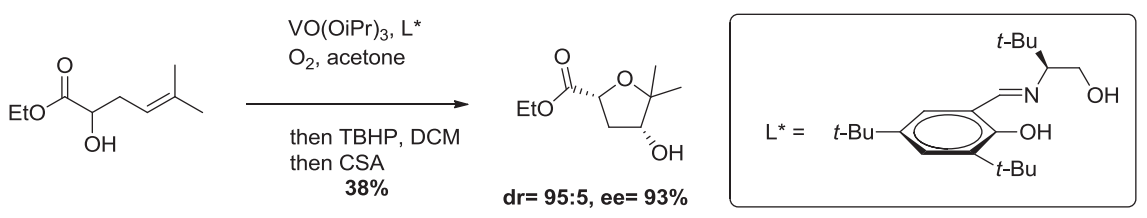

Scheme 3. Homoallylic alcohol resolution and cyclization.

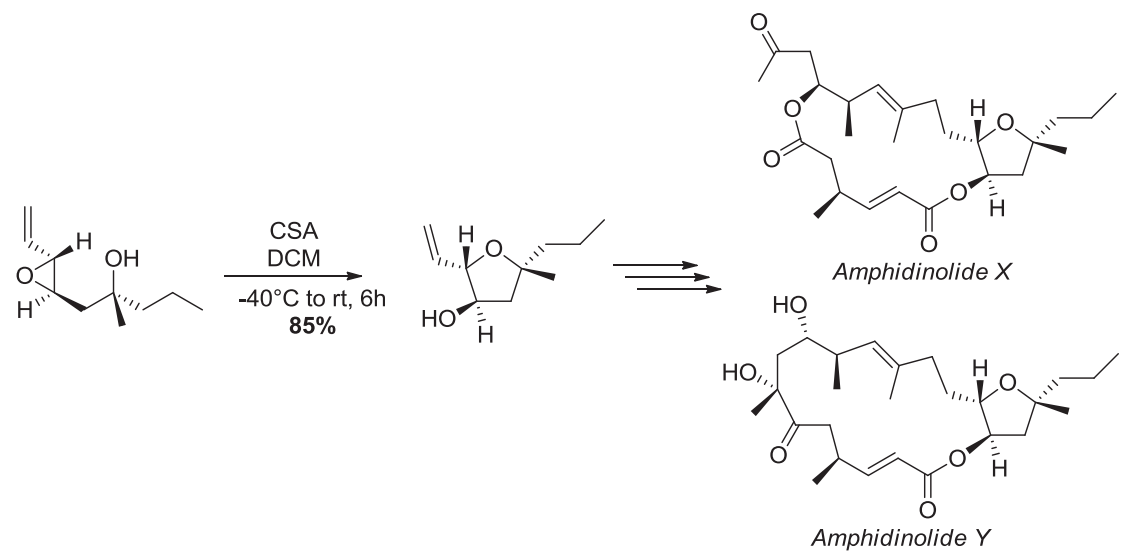

Scheme 4. Toward the synthesis of Amphidinolides $\mathrm{X}$ and $\mathrm{Y}$.

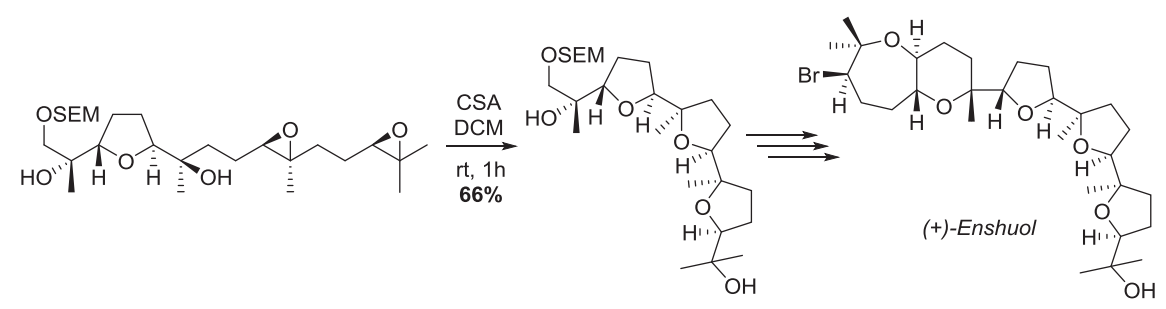

Scheme 5. Opening epoxide cascade for the synthesis of (+)-Enshuol.

In addition to the above-mentioned CSA procedure, mild acid conditions were used by the team of Paton and Burton toward the syntheses of Laurefurenynes A and B. The authors actually observed during the Sharpless dihydroxylation process, the formation of small amount of the cyclization product. Thus, Amberlyst-15 resin was used to complete the cyclization step (Scheme 6). ${ }^{26}$

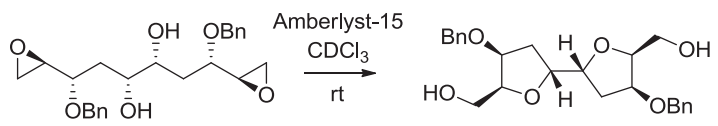

Scheme 6. Amberlyst-15 promoted cyclization for the synthesis of model 2,2'bifuranyls.
Interestingly, Martin and Martin wanted to take advantage of the formation of a hexacarbonyldicobalt stabilized propargylic cation in acidic conditions to induce the cyclization step (Scheme 7 ). ${ }^{27}$ Toward this end, several acids were tested: $\mathrm{BF}_{3} \cdot \mathrm{Et}_{2} \mathrm{O}$ resulted in the degradation of the starting compound and gentle Montmorillonite K-10 acid remained inefficient. Finally, the authors observed the desired cyclized product after purification on silica and could therefore carry out the cyclization step using $\mathrm{SiO}_{2}$ in dichloromethane, followed by deprotection using CAN, which allowed them to complete the synthesis of Teurilene.

In these mild acidic media several protecting groups remained stable such as ethers (TBS, TBDPS, SEM, PMB, Bn), carbonate (Boc), acetonide group or sulfonate (Mesyl). 


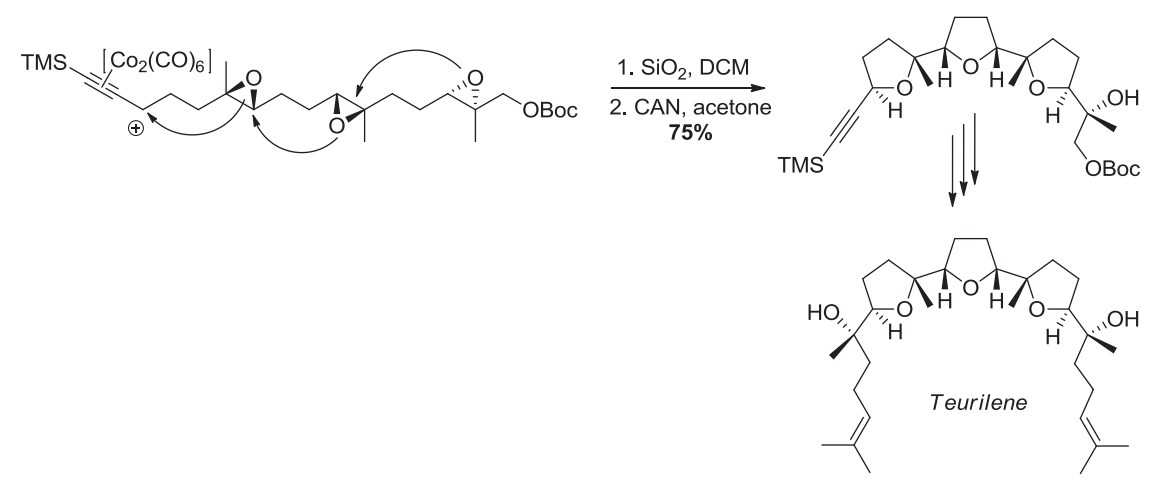

Scheme 7. Mild acidic condition for the synthesis of the 2,5-disubstituted tetrahydrofuran moieties of Teurilene.

Epoxide opening cyclizations were also carried out using basic conditions and in recent syntheses two groups have used hydroxydes ( $\mathrm{LiOH}, \mathrm{NaOH}$, and $\mathrm{KOH}$ ) for this purpose. The teams of Morimoto and Galano-Oger performed a Payne rearrangement which induced a 5-exo-tet cyclization for the synthesis (+)-Intricatetraol, $^{28}(+)$-Omaezakianol, ${ }^{29}$ and Phytofuran (Scheme 8). ${ }^{30}$

\subsection{Haloetherifications and halogen substitutions}

The first reports of an enantioselective haloetherification were made by the team of Kang, using $\mathrm{Co}^{\text {III }}$-salen, Ti-BINOL or $\mathrm{Cr}^{\mathrm{III}}$-salen catalysts. $^{36-38}$ Haloetherifications allow the cyclization of a dihomoallylic alcohol to produce a THF substituted by a halide. This

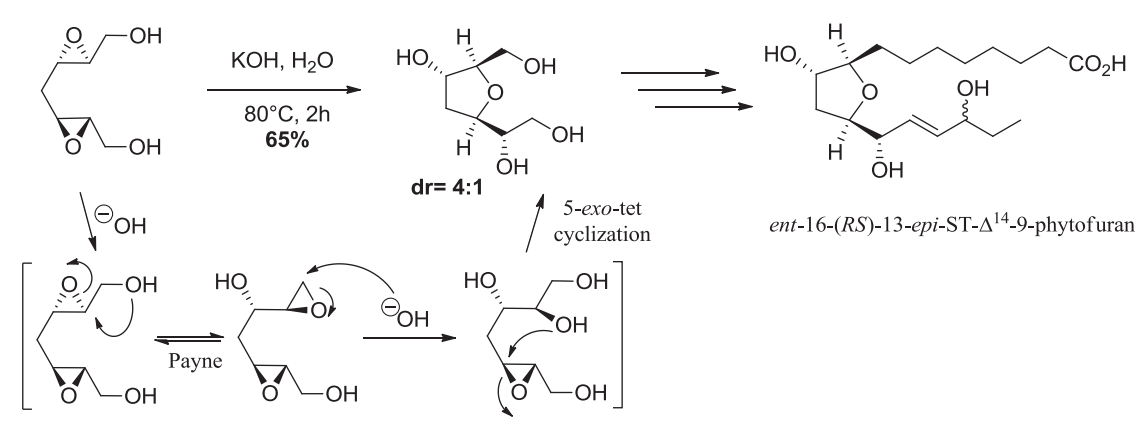

Scheme 8. Payne rearrangement followed by 5-exo-tet cyclization for the synthesis of ent-16(RS)-13-epi-ST- $\Delta^{14}-9-$ phytofuran.

In addition, toward the synthesis of isofurans, the team of Taber used potassium carbonate in order to induce the cyclization. ${ }^{31-33}$

Few functional groups were present on the substrates in those syntheses, such as ethers (Bn, Tr) and acetals. It is thus difficult to conclude on the tolerance of functional groups under those basic conditions.

Finally, some epoxide opening reactions proceeded without the need of further catalysis, after the epoxidation step. For instance, a tandem epoxidation/cyclization reaction using $\mathrm{VO}(\mathrm{acac})_{2}$ catalyst and tert-butylhydroperoxide (TBHP) or cumene hydroperoxide (CHP) was nicely reported by the groups of Carreira ${ }^{34}$ (Scheme 9) and Pihko, ${ }^{35}$ respectively. process is particularly interesting as it allows further postfunctionalizations. However, enantioselective processes are scarce, as the stereochemical information is often lost during halonium transfers, which are kinetically competitive with the cyclization. ${ }^{39}$ While these quick halonium transfers usually prevent enantioselective processes, they allow diastereospecific haloetherifications. Thus, Ramos et al. recently reported an iodocyclization method to get trans-THF (Scheme 10). ${ }^{40}$ In this case, the iodonium transfer sets equilibrium between the two diastereomers of the iodonium, which is displaced towards the most stable diastereomer.

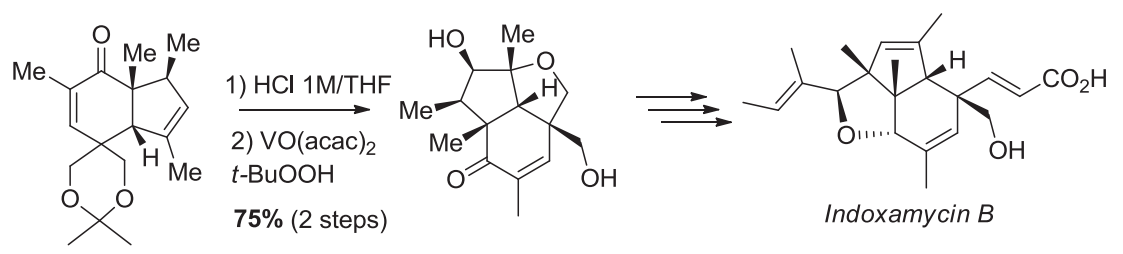

Scheme 9. Total synthesis of (rac)-Indoxamycin B. 

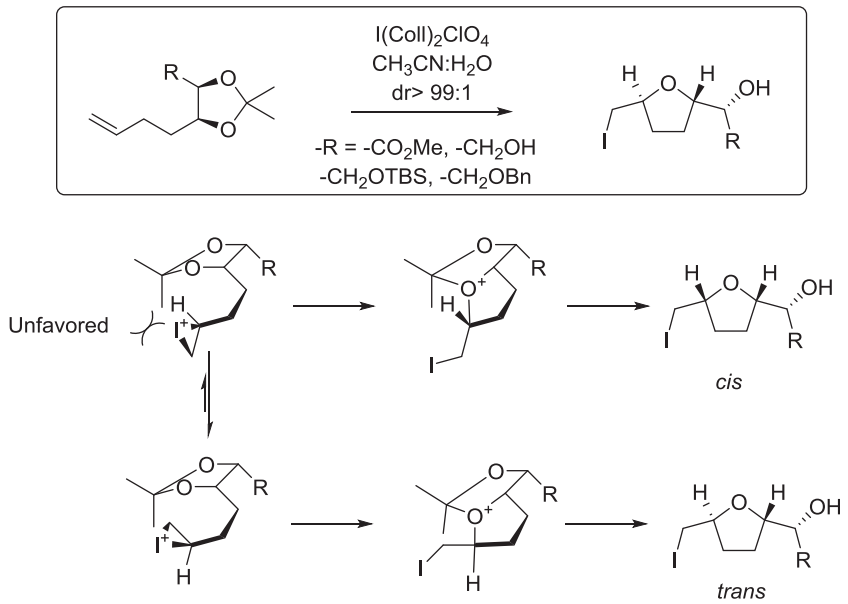

Scheme 10. Diastereospecific iodocyclization to form trans-THF.

Another diastereospecific iodocyclization was recently developed by Fujioka et al., yielding cis-THF derivatives. ${ }^{41}$ This method is based on a TMS transfer, triggered by trimethylsiloxycyclohexene, to generate a steric bulk that will allow the cis-selectivity (Scheme 11). In this case, the cis-THF products are obtained in very good yields and good diastereoselectivies (dr up to 15:1).

More recently, an enantioselective bromoetherification reaction was described by Huang et al., catalyzed by a chiral phosphoric acid in the presence of NBS. ${ }^{42}$ This method gave the corresponding 2substituted THF in excellent yields and, in some cases, good enantioselectivities (58-81\% ee). A few months later, a similar method was presented by Denmark et al. with for the first time a rationalization of the enantioselectivity. ${ }^{43}$ In this work, the authors explain that the loss of enantioselectivity due to the bromonium transfer is overcome by associating a chiral counter-ion to the chiral bromonium, in order to keep the enantioselectivity during the bromonium transfer (Scheme 12). Another approach to make an enantioselective haloetherification was described by Hennecke et al. in 2011. ${ }^{44}$ This method is a desymmetrization based on the formation of a meso-halonium intermediate. The presence of the sodium salt of a chiral phosphoric acid, associated to the halonium salt, makes the irreversible cyclization step the stereo-determining step, ensuring decent enantioselectivities (ee up to 71\%). Although the scope of this reaction is somewhat limited, the method allows both bromo- and iodo-etherification in good yields.

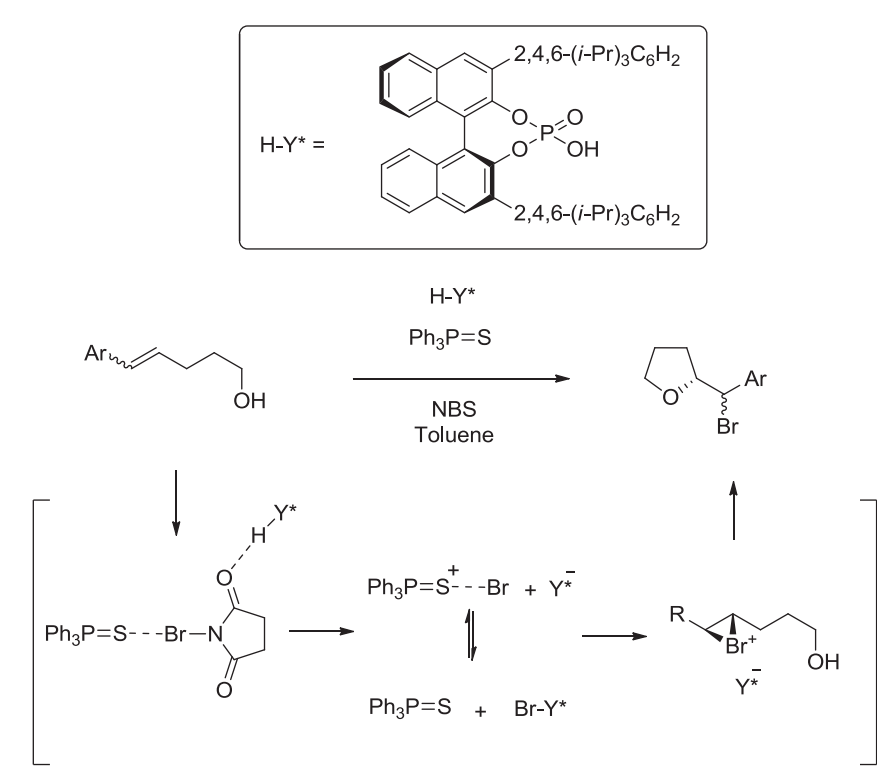

Scheme 12. Rationalization of the enantioselectivity in the chiral phosphoric acidcatalyzed bromoetherification.

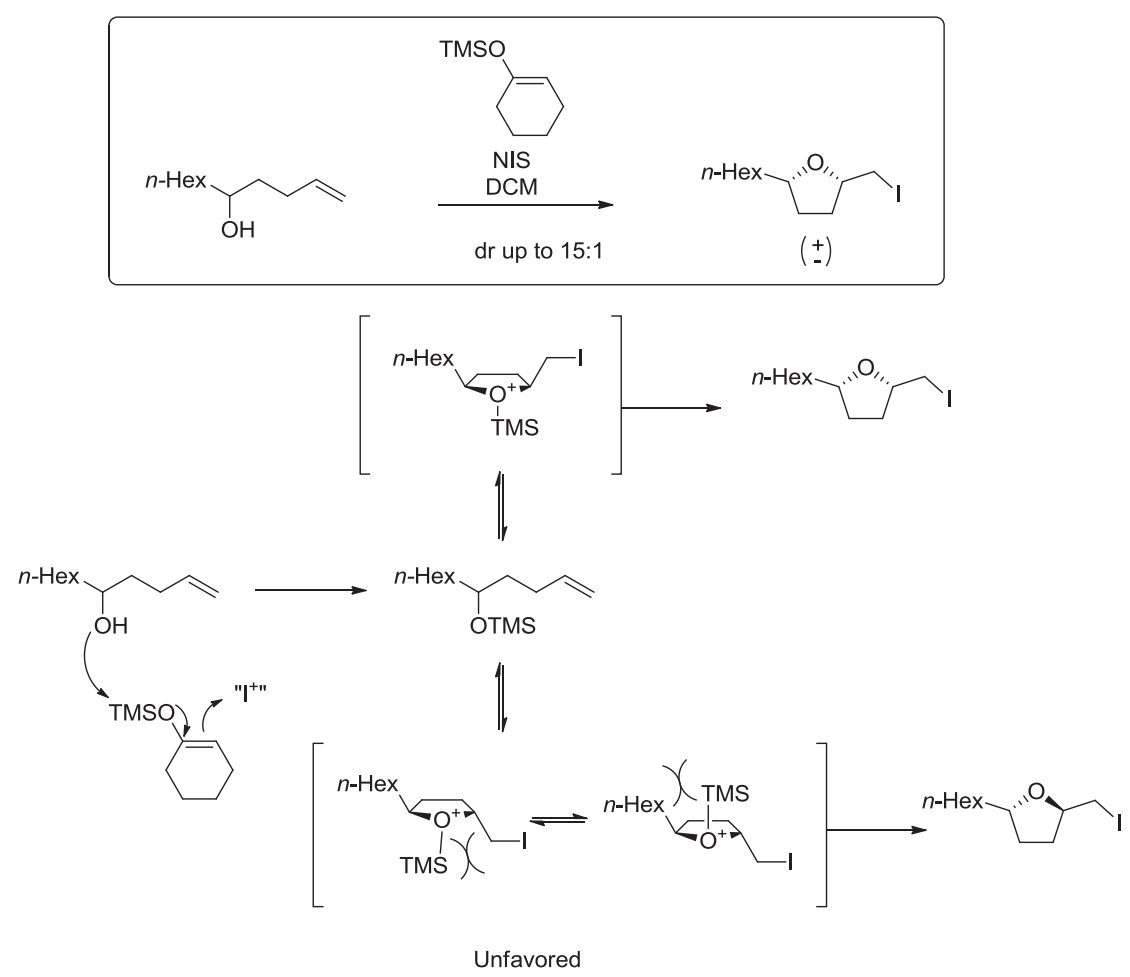

Scheme 11. cis-Selective iodocyclization. 
The latest advance in the field of enantioselective haloetherifications was presented by Tay et al., who performed the desymmetrization of a diene-diol by a double bromoetherification. ${ }^{45}$ The process works in two steps: a first bromoetherification catalyzed by a quinidine derivative allows the desymmetrization, and then a second bromoetherification occurs, with the stereoselectivity controlled by the stereogenic centers formed during the first step (Scheme 13). configuration of the substituents in positions 2 and 3 is determined by the configuration of the alkene in the substrate.

Simpler halide substitutions were widely developed for the synthesis of THF. Recently, the group of Britton studied the formation of oxolanes starting from chloropolyols. Thus, an enantiospecific aldolreduction-cyclization sequence was published in 2009, allowing an access to various diastereomers of a hydroxyl-bearing THF, all in very good yields and diastereoselectivities (Scheme 14). ${ }^{47}$ Two diaster-

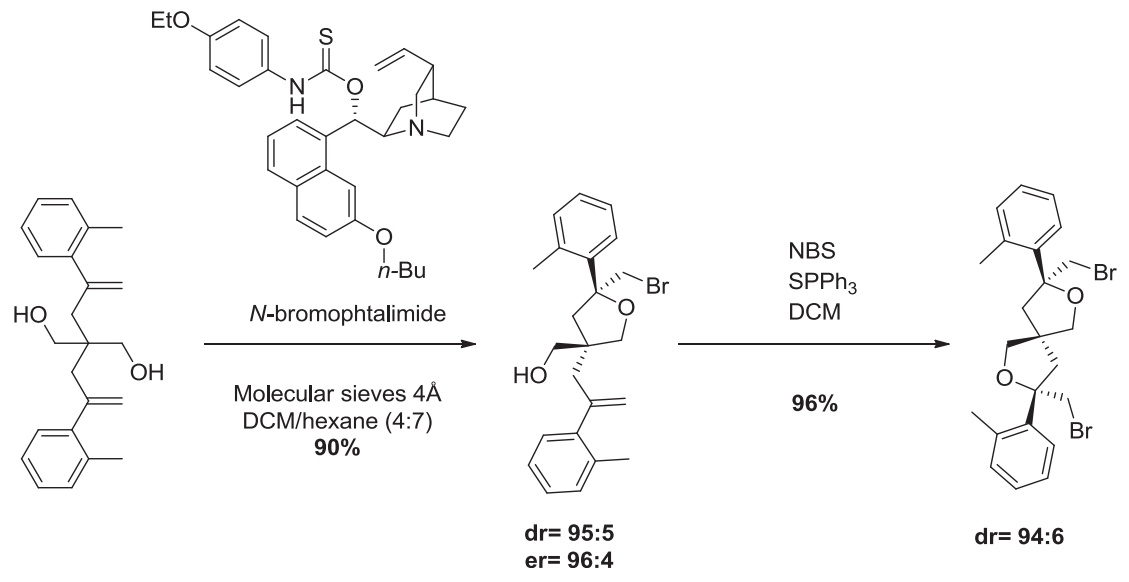

Scheme 13. Diene diol desymmetrization by bromoetherification.

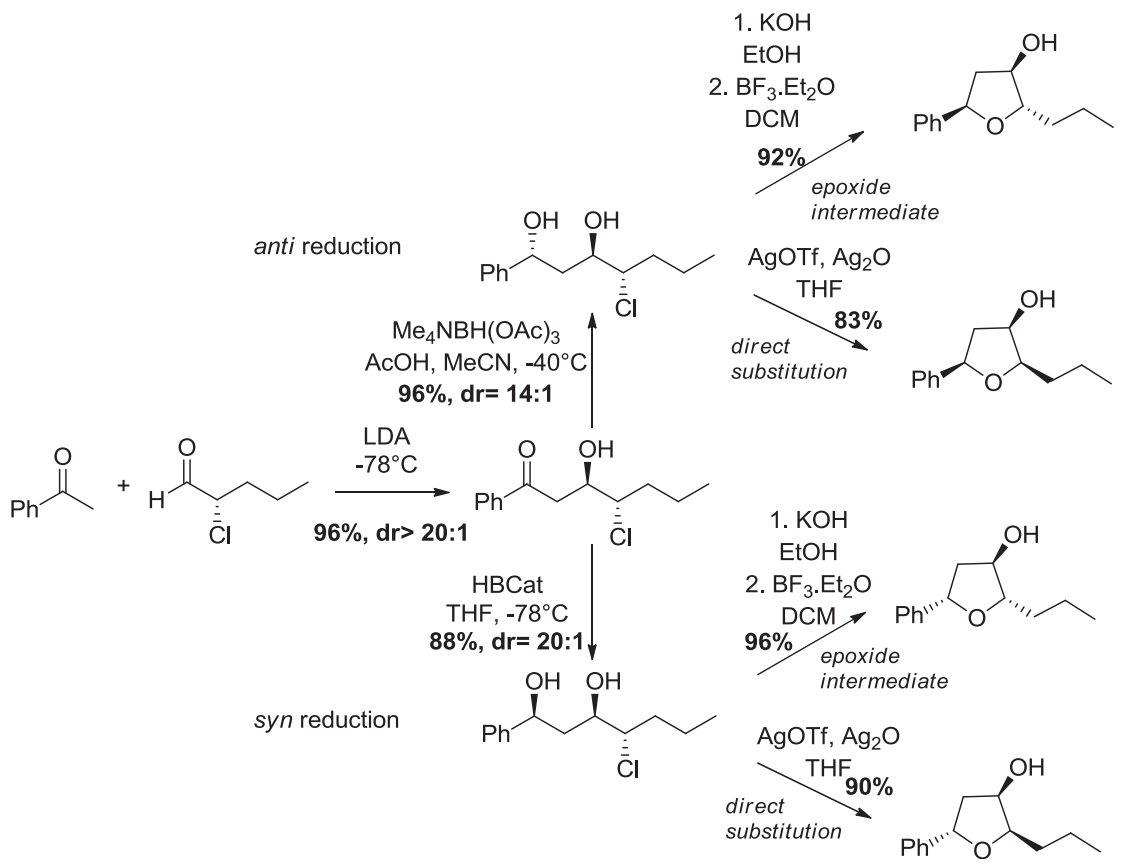

Scheme 14. Chloropolyol cyclization into THF.

Cinchona alkaloids were also used for chloroetherification by Zeng et al. in a diastereospecific and enantioselective process. ${ }^{46}$ Remarkably, this method allows a 5-endo-tet cyclization to synthesize 2,3-disubstituted THF, bearing a chloro-substituent in position 3 and an aromatic substituent in position 2, in good yields and excellent enantioselectivities (ee up to 96\%). The relative eodivergent cyclization processes were described, one through the formation of an epoxide intermediate opened in a 5-endo-tet cyclization and leading to a global retention of configuration, and the other through a direct substitution of the chloride, leading to Walden-type inversion of configuration. Later, the same team reported a cyclization of chloropolyol in water, allowing a mild formation of $\mathrm{THF}^{48}$ 
The work of Britton and co-workers was successfully applied to the synthesis of Laurefurenynes A and $\mathrm{B}^{49}$ and Ascospiroketal A. ${ }^{50}$ The first synthesis was performed in 2013 where they applied the AgOTf $/ \mathrm{Ag}_{2} \mathrm{O}$ system to obtain two tetrahydrofuranol moieties in good yields (67\% and 52\%) (Scheme 15).
Although protecting group compatibility with these conditions has not been formally evaluated during those NBS or TBCOmediated cyclizations, ester (Piv), ethers (TBDPS, Bn), and acetal groups were all tolerated.

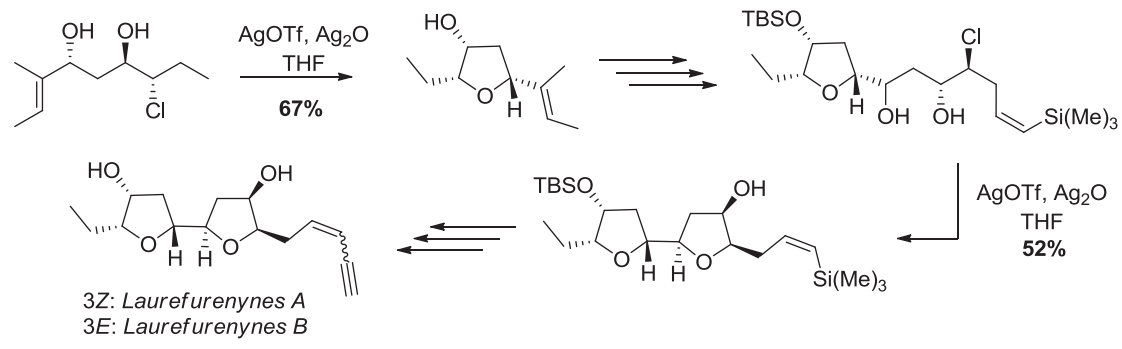

Scheme 15. Total synthesis Laurefurenynes A and B by Britton.

For the synthesis of Ascospiroketal A, the above-mentioned conditions proceed smoothly to give the desired intermediate. Nevertheless, the change of the triflate $\left(\mathrm{OTf}^{-}\right)$counteranion by tetrafluoroborate $\left(\mathrm{BF}_{4}^{-}\right)$improved the yield of the reaction (Scheme 16).
Following a similar mechanism, selenoetherification and mercuroetherification were also used for the synthesis of natural products. $N$-(Phenylselenyl)phthalimide was used for the synthesis of the 11-epi-mandelalide $\mathrm{A}$, by the group of Fürstner, ${ }^{55}$ while phenylselenylchloride was used by the group

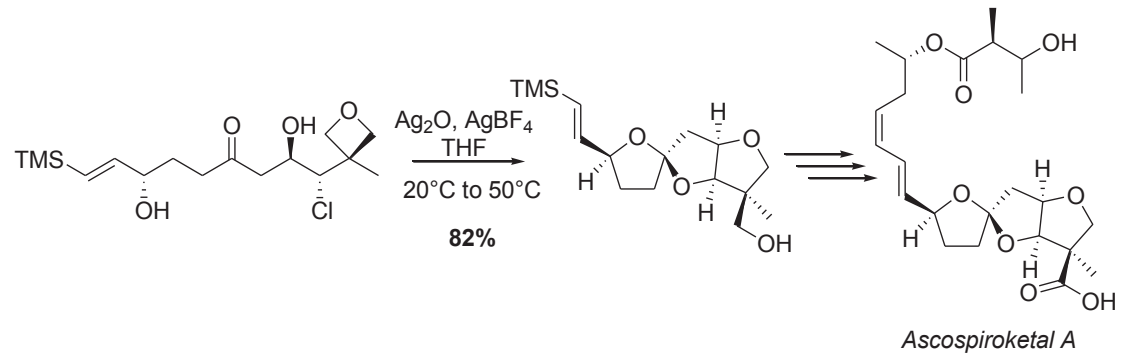

Scheme 16. Total synthesis of Ascospiroketal A by cyclization cascade using $\mathrm{AgBF}_{4} / \mathrm{Ag}_{2} \mathrm{O}$.

As far as we know, the two syntheses described above are the only ones using the recent halogen substitution methodologies. Although, several syntheses were realized thanks to bromoetherification reactions, using $\mathrm{NBS}^{51-53}$ or the tetrabromocyclohexadienone (TBCO). ${ }^{54}$

Thus, the formal synthesis of Obstusallenes II and IV proceeded using $\mathrm{TBCO}^{54}$ and the total syntheses of Gambieric Acid $\mathrm{A},{ }^{52}$ the unnatural Omaezallene, ${ }^{53}$ and Laureatin ${ }^{51}$ were attempted using NBS.

The group of Howell was interested in the synthesis of Laureatin ${ }^{51}$ and was surprised not to observe the desired eight member ring product but a 2,3,5-trisubstituted furan. Indeed, the cyclization did not proceed directly from the free hydroxyl group onto the olefin, but through the opening of the oxetane (Scheme 17). The epoxy-THF was isolated in 51\% yield as a single diastereomer. The assignment of stereochemical relationship of the epoxy-THF was realized by further derivatization and X-ray analysis. of Ma for the synthesis of Leucosceptroids A and B. ${ }^{56}$ One recent example of a synthesis using mercuroetherification was also achieved by Mohapatra and co-workers, using mercury (II) acetate. $^{57}$

\subsection{Allylic and propargylic alkylations}

Since their discovery in 1977 by Trost, ${ }^{58}$ allylic alkylations have stood out as a powerful method in organic synthesis. ${ }^{59}$ This approach also suits to the synthesis of THF. Thus, the team of Spilling recently developed a palladium catalyzed method to form oxolanes from phosphono-allylic carbonates (Scheme 18). ${ }^{60}$ This method also permits the formation of larger cycles, up to eight membered rings.

The allylic alkylation was also applied by Olszewska et al. to form tetrahydrofurans by desymmetrization of 1,3-diols. ${ }^{61} \mathrm{Al}$ though this reaction usually shows good yields (80-99\%), the

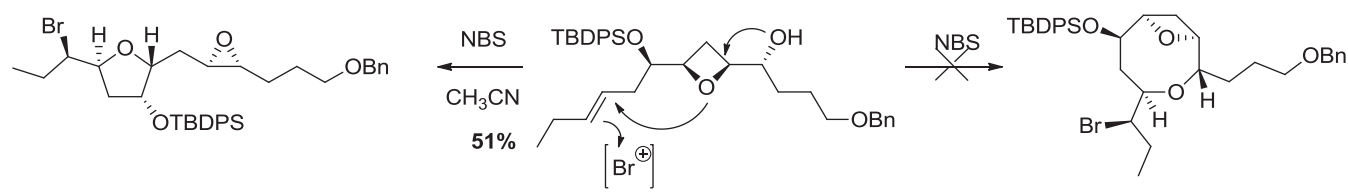

Scheme 17. Unexpected cyclization toward the synthesis of Laureatin. 


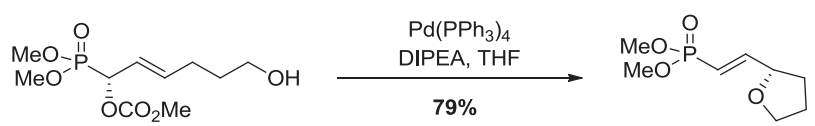

Scheme 18. Palladium catalyzed synthesis of THF from phosphono-allylic carbonates

diastereomeric and enantiomeric ratios are moderate with all ligands tested (Josiphos, Trost's ligands, phosphoramidites, and chiral phosphines).

More recently, Roulland realized the synthesis of (+)-Oocydin A and demonstrated that the principle of asymmetric counteraniondirected catalysis (ACDC) could be applied to the synthesis of tetrahydrofurans. ${ }^{62}$ Later, Gandon and Roulland studied this reaction by DFT calculations. ${ }^{63}$ The authors concluded that during the formation of a THF from a diol, the unreactive hydroxyl function controlled the stereochemical outcome of the reaction by complexing the palladium through the acetyl counteranion (Scheme 19). Therefore, this method allows to form 2,3,5-trisubstituted THF with very good diastereoselectivities (dr up to 96:4), but only when the substituent in position 3 is a free hydroxyl function.
Then, Zanoni and co-workers accomplished the synthesis of two tetrahydrofurans needed for the synthesis of neurofurane thanks to Trost allylic alkylation. Starting from a meso-diol, the authors performed a desymmetrization reaction followed by the consecutive formation of the tetrahydrofurans in good yields as well as diastereomeric and enantiomeric ratios (Scheme 21). ${ }^{70}$

Trost also successfully applied this reaction to the synthesis of C13-C29 fragment of Amphidinolide N which permits access to the desired trans-THF with $4.6: 1 \mathrm{dr}$ and $82 \%$ yield (Scheme 22). ${ }^{71}$

Finally, the group of Liu obtained the tetrahydrofuran motif for the total synthesis of Leucosceptroid $\mathrm{B},{ }^{72}$ by a one-pot rearrangement-deprotection cascade. The author proposed a mechanism involving the activation of tertiary allylic hydroxyl group with a Lewis acid leading to an intramolecular oxa-Michael addition, prior to the cleavage of the MOM and TBS protecting groups (Scheme 23).

\subsection{Other nucleophilic substitutions}

Oxolanes can be synthesized by nucleophilic substitutions of other leaving groups. For example, Minuti et al. recently reported

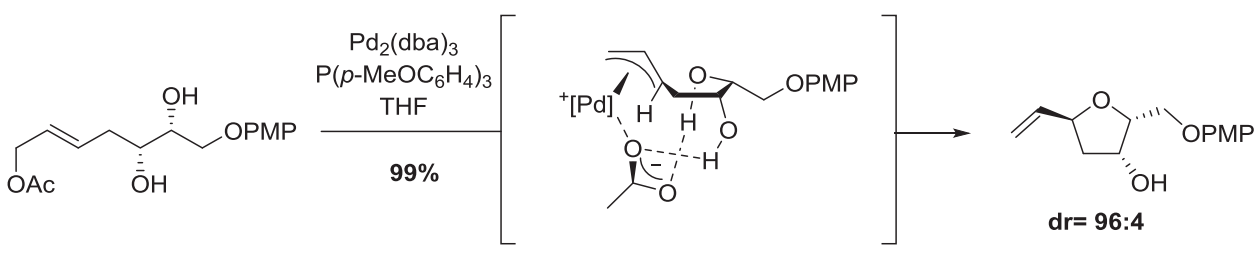

Scheme 19. Stereoselective formation of oxolanes by ACDC.

In addition, Brovetto et al. reported in 2008 a method to synthesize THF from an allylic acetate, by one-pot acetonide deprotection-cyclization-acyl transfer through a dioxonium intermediate under acidic conditions. ${ }^{64}$ This approach allows the formation of highly substituted THF patterns, in decent yield and with good stereocontrol.

Except for the reaction developed by Roulland, which was extended to the synthesis of the $(+)$-Oocydin $A,{ }^{62}$ all the recent syntheses reporting allylic alkylation reactions used Trost conditions. In this way, the formal synthesis of fragment C18-C34 of Amphidinolide $\mathrm{C}$ and $\mathrm{C} 18-\mathrm{C} 29$ of Amphidinolide $\mathrm{F}$ was achieved by Roy et al. in 2010 using $\operatorname{Pd}(0)$ catalyzed cyclization for the obtention of the tetrahydrofuran, ${ }^{65}$ as well as oxylipids isolated from Australian algae Notheiaanomala. ${ }^{66}$ Besides, the group of McErlean reported the formation of 2,5-disubsituted-3-oxygenated tetrahydrofuran, a useful building block for the synthesis of (+)-kumasuallene, ${ }^{67}$ using Pd-catalyzed alkoxy-carbonylation conditions developed by Semmelhack ${ }^{68}$ (Scheme 20). The same procedure was recently applied by Gracza for the formal synthesis of (+)-Pyrenolide D (Scheme 20). ${ }^{69}$

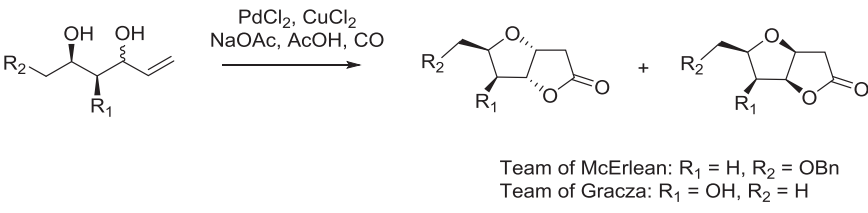

Scheme 20. Palladium catalyzed allylic alkylation to formation of THF core. a simple synthetic sequence to obtain 2-substituted THF by substitution of a selenone moiety. ${ }^{73}$ The enantioselectivity is obtained by a Corey-Bakshi-Shibata reduction to form the alcohol, and no
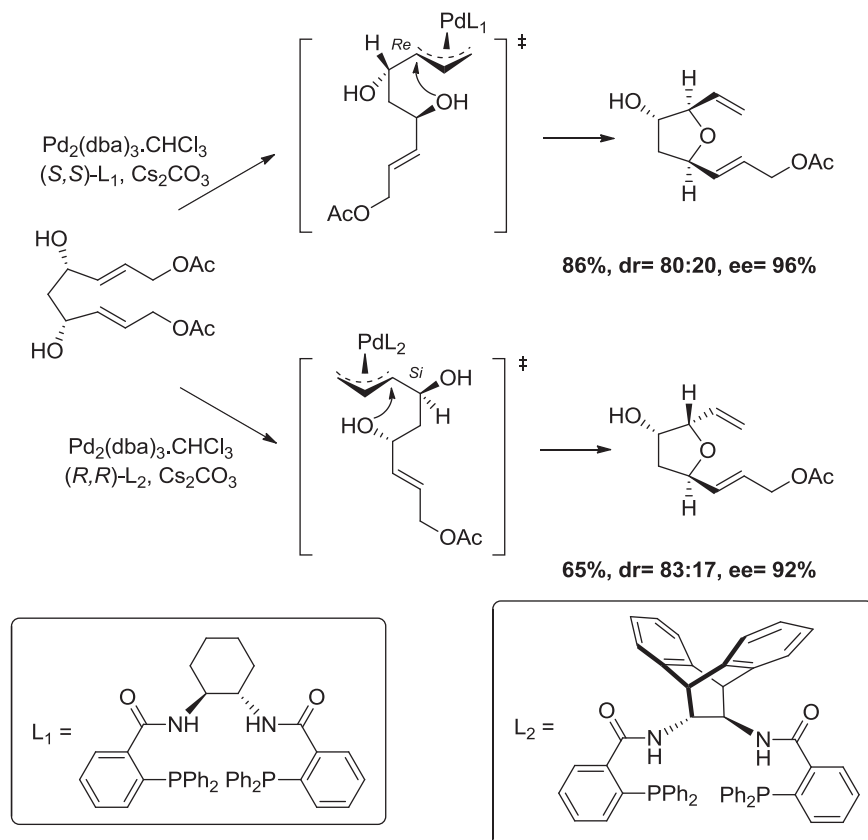

Scheme 21. Desymmetrization followed by cyclization using $\operatorname{Pd}(0)$. 


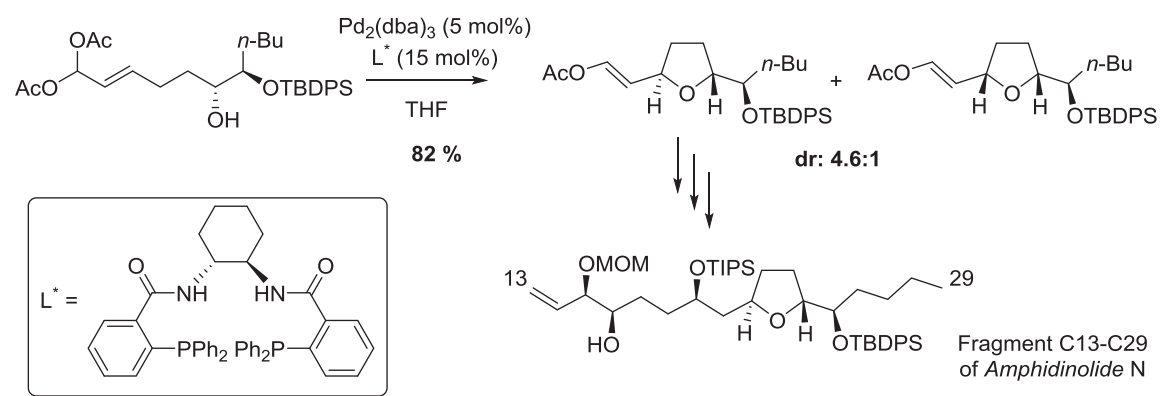

Scheme 22. Pd-catalyzed asymmetric allylic alkylation for the synthesis of C13-C29 fragment of Amphidinolide N.

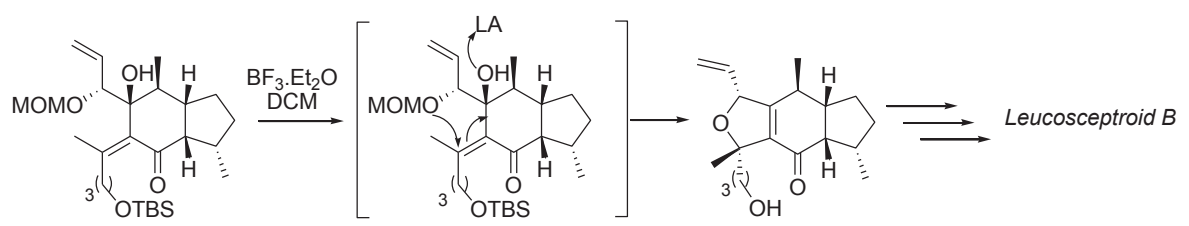

Scheme 23. Synthesis of Leucosceptroid B by one-pot rearrangement-deprotection cascade activated by Lewis acid.

erosion of the enantiomeric excess is observed during the cyclization (Scheme 24).

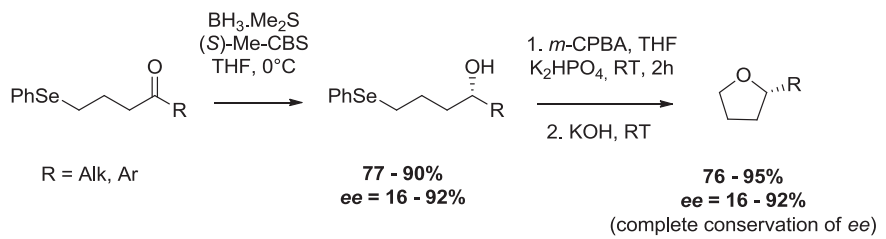

Scheme 24. CBS reduction-selenone substitution sequence.

Similarly to epoxides, oxetanes can be opened by hydroxyl groups. Thus, a $\mathrm{CO}^{\mathrm{III}}$-salen catalyzed desymmetrization was proposed by the group of Jacobsen, to synthesize, among other structures, THF in excellent yields (up to $98 \%$ ) and ee (up to $99 \%$ ). ${ }^{74}$ This kind of reactivity was recently observed by Keshipeddy et al. while trying to synthesize the oxetane-containing eight-membered ring of Laureatin (previously described, see Scheme 17). ${ }^{51}$ An undesired cyclization by opening of the oxetane during a bromocyclization led the authors to a substituted THF through a 3-exo-tet/5-exo-tet cascade cyclization.

Romo and co-workers developed a strategy allowing access to THF by assembling three building blocks, ${ }^{75}$ either in two steps or using a one-pot process. ${ }^{76,77}$ This strategy is based on the formation of a $\beta$-lactone by a Mukaiyama-aldol-lactonization sequence, followed by a reductive cyclization through the energetically favored ring opening of the $\beta$-lactone, to form an oxonium intermediate which is trapped in situ by a nucleophile (Scheme 25).
Analogous to epoxides, orthoesters used as electrophiles, can also lead to THF. This was developed by the group of Borhan, promoting a Lewis acid-catalyzed cyclization of 1,2,n-triols with the stereoselectivity controlled in advance by Sharpless asymmetric dihydroxylation. ${ }^{78}$ Notably, this method allowed the formation of THF bearing an acetate in position 3 by 5-endo-tet cyclizations, unfavored according to Baldwin's rules.

Borhan used the Lewis acid catalyzed cyclization developed by his group for the synthesis of Mucoxin. ${ }^{79}$

Later, the group of She used Borhan cyclization procedure for the total synthesis of $(+)$-monocerin. ${ }^{80}$ More recently, the group of Galano-Oger applied it for the syntheses of dihomo-isofurans and neurofuran (Scheme 26), ${ }^{81,82}$ in a divergent strategy using 5-exo-tet and 5-endo-tet cyclizations.

Few protecting groups have been carried through the cyclization conditions using Lewis acid. Those that have include PMB or benzyl ethers, ethyl ester, and benzoyl group. It should be noted that TBS can undergo partial deprotection and/or migration and that PMB was partially cleaved.

Orthoesters, oxetanes and epoxides are not the only groups to allow the formation of THF. Other leaving groups such as aziridines, ${ }^{83}$ carbonates, ${ }^{84}$ sulfonates, ${ }^{85-87}$ thioethers, ${ }^{88}$ PMB ether, ${ }^{89}$ carbamate $^{90}$ were studied and recently applied in total synthesis. The sulfonate groups (Ms or Ts) were used by the groups of Barker, Ghosh, and Zhao for the synthesis of Fragransin $\mathrm{A}_{2},{ }^{85}$ Mandelalide $A,{ }^{87}$ and Amphidinolide T3, ${ }^{86}$ respectively. The team of Martinková used a carbamate during the synthesis of the chloride salt of pachastrissamine. ${ }^{90}$ Less common, the PMB ether was a good protecting and leaving group during the acid-promoted synthesis

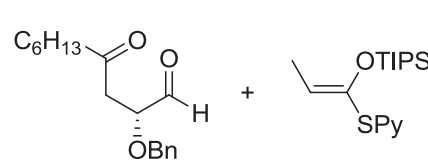

$( \pm)$

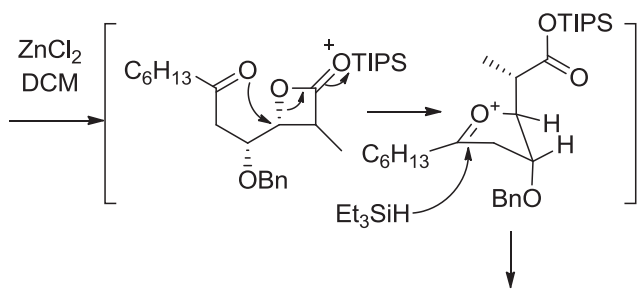

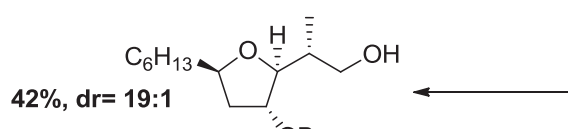

$( \pm)$<smiles>C[C@@H]1C[C@H]([AsH2])O[C@@H]1[C@@H](C)C(=O)O[SnH]</smiles>

$( \pm)$

Scheme 25. THF formation by reductive cyclization. 


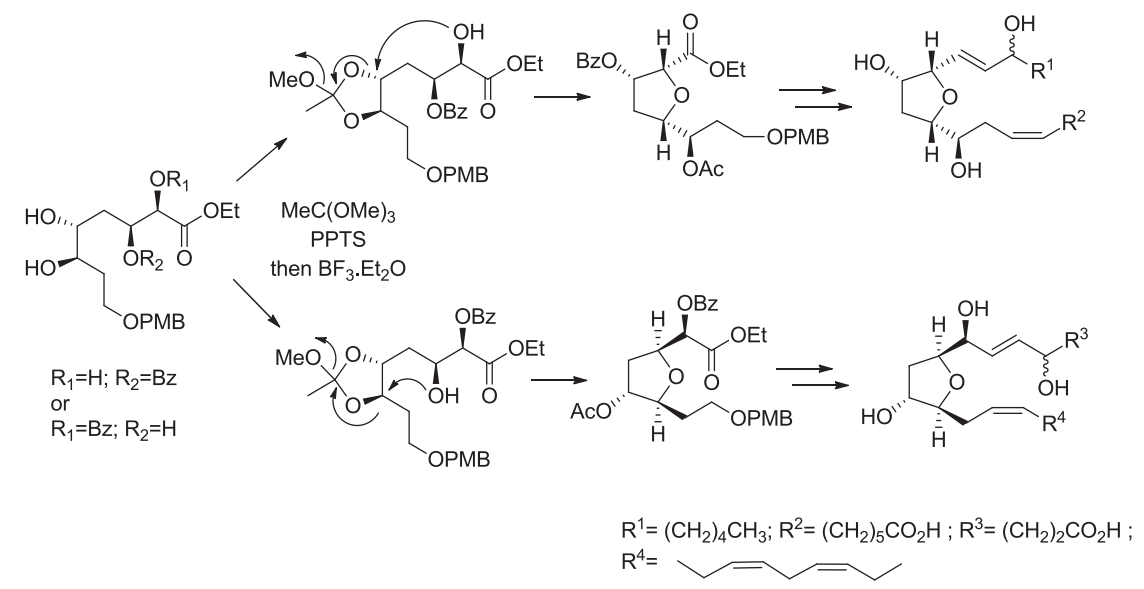

Scheme 26. 5-exo and 5-endo-tet cyclizations using Borhan conditions for the synthesis of dihomo-isofuran and neurofuran.

of spiroketal units of pectenotoxin proposed by Pihko et al. ${ }^{89}$ Unfortunately, no matter which the acid tested a mixture of kinetic and thermodynamic spiroketals is observed, with as a best result chloroacetic acid (49\% yield with $5 \%$ of the epimer).

Finally, an $\mathrm{S}_{\mathrm{N}} 1$-type reaction was proposed by the team of Pandey where the Evans aldol reaction using $\mathrm{TiCl}_{4}$ resulted in the cleavage of the TBS group followed by an intramolecular substitution on the benzylic position (Scheme 27). Piperonal and $p$ anisaldehyde were used as aromatic aldehydes, and the latter afforded the synthesis of $(+)$-Magnolone. ${ }^{91}$
However, most of the recent innovations are related to goldcatalyzed allene hydroalkoxylations. This process was developed by the group of Widenhoefer and takes advantage of the relative fragility of allenes $\pi$-bonds to form THF bearing an alkenyl function (Scheme 29). ${ }^{94,95}$ This strategy was also employed by Alcaide et al. in a regiodivergent cyclization leading to THF structures and oxepanes. $^{96}$

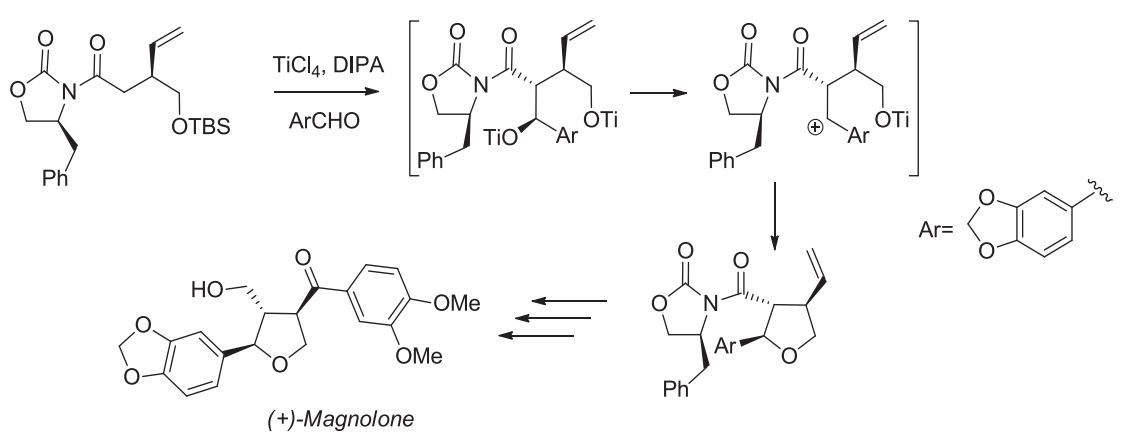

Scheme 27. Evans aldol reaction followed by intramolecular $\mathrm{S}_{\mathrm{N}} 1$ for the synthesis of THF.

\subsection{Hydroalkoxylations}

Hydroalkoxylation is a direct and atom-economic reaction to form THF derivatives. The addition usually takes place in a 5-exotrig mode, according to Baldwin's experimental rules. ${ }^{92} \mathrm{~A}$ recent method developed by Lambert and co-workers allows a nucleophilic addition on an aldehyde followed by a hydroalkoxylation of the resulting alcoholate (Scheme 28). ${ }^{93}$ Both processes are catalyzed by $\mathrm{Bi}(\mathrm{OTf})_{3}$ in one-pot, and the resulting trans-THF are formed in excellent yield (up to 94\%) and good diastereomeric ratio (up to 6.8:1).

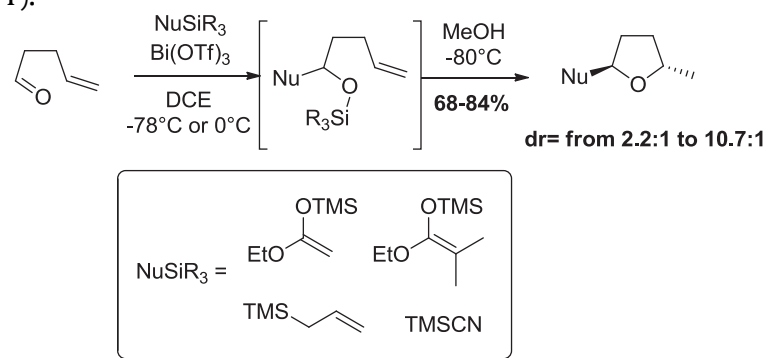

Scheme 28. Tandem addition/hydroalkoxylation reactions.

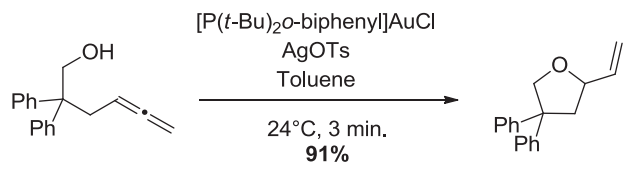

Scheme 29. THF formation by allene hydroalkoxylation.

Following on from his work on allylic alkylations, Trost reported in 2009 primary and secondary propargylic alcohol isomerizations followed by an intramolecular addition of alcohol, for the preparation of tetrahydropyrans and tetrahydrofurans, using $\left[\mathrm{InRu}\left(\mathrm{PPh}_{3}\right)_{2} \mathrm{Cl}\right.$ ] catalyst. ${ }^{97}$ The reaction conditions are compatible with ynol esters and silyl groups such as TIPS or TBDPS. Although this methodology gives good yields and diastereoselectivities for the preparation of tetrahydropyrans ( $\mathrm{dr}$ up to $40: 1$ ), poor $\mathrm{dr}(1: 1)$ were obtained for the furans (Scheme 30).

As was previously mentioned, the same diastereoselectivity (1:1) was obtained when the conditions were applied to the synthesis of $\mathrm{C} 13-\mathrm{C} 29$ fragment of Amphidinolide $\mathrm{N}^{71}$ Thus, the strategy was revised to access to an olefin using the Pd-catalyzed asymmetric allylic alkylation previously developed (see Scheme 22). 


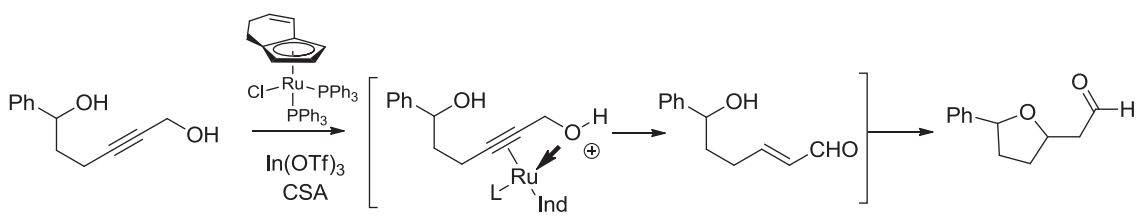

Scheme 30. Isomerization-conjugate addition for the formation of tetrahydrofurans.

It is worth noting that the above methodologies have not yet been applied to total synthesis. This may be rationalized by their recent development. Nevertheless, hydroalkoxylations are used in total synthesis in many ways.

TBAF was employed by the groups of Arya and Fürstner for the synthesis of Eribulin fragment ${ }^{98}$ and Amphidinolide $C$ and $F$, respectively, ${ }^{99,100}$ to deprotect and mediate the cyclization step. In addition, a cobalt catalyzed cyclization process was studied by the team of Forsyth in 2013. ${ }^{101}$ They realized the synthesis of the C15-C25 fragment of Amphidinolide C using Hartung's cobalt catalyst (Scheme 31).

\subsection{Cross-coupling}

Some palladium-catalyzed processes also involve an alkoxylation step between a hydroxyl group and an alkene. This alkoxylation is usually in tandem with an intermolecular coupling of an aryl bromide, as reported by Ward et al., ${ }^{105}$ or an acetylenic bromide as presented by the group of Waser (Scheme 33). ${ }^{106,107}$ This kind of method usually displays excellent yield and diastereomeric ratio. In a similar way, a palladium-catalyzed coupling of 3,5dihydroxyalkenes followed by a carbonylation allows the access

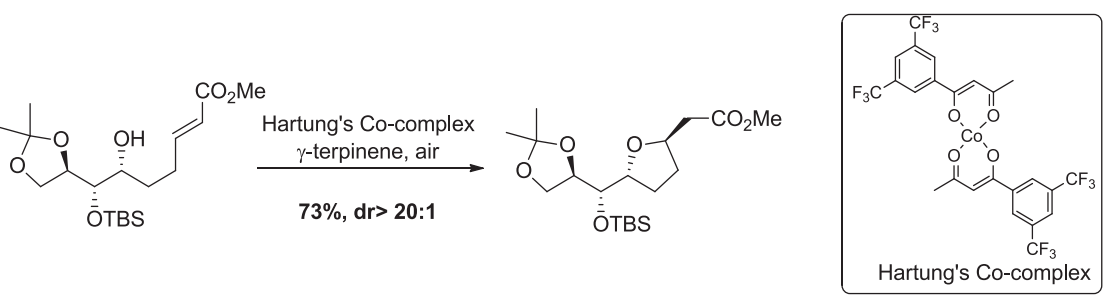

Scheme 31. Cobalt-catalyzed modified Mukaiyama alkenol cyclization for the synthesis of the C15-C25 fragment of Amphidinolide C.

Few examples were reported in total synthesis using basic hydroalkoxylations. The first one was achieved using Triton B (benzyltrimethylammonium hydroxide) in methanol, by the group of Kigoshi for the synthesis of Haterumalide NA. ${ }^{102}$ The second one, was realized by the team of Ding during the total synthesis of (-)-Indoxamycins A and $\mathrm{F}^{103} \mathrm{~A}$ tandem oxa-Michael addition/ methylenation promoted by a Grignard reagent was thus achieved in good yield and enantiomeric excess (Scheme 32). Finally, for the synthesis of ent-Heliespirones A and C, Bai et al. reported the use of $\mathrm{Cs}_{2} \mathrm{CO}_{3}$ in DCM to achieve a spirocyclization. ${ }^{104}$ to THF-lactone bicycles, which are interesting building blocks for the synthesis of natural products. ${ }^{67}$

It is worth noting that to our knowledge, there is no recent use of cross coupling reaction for the formation of THF derivatives in total synthesis.

\subsection{Oxidative cyclizations}

Oxidative cyclization was serendipitously discovered in 1965 by Klein and Rojahn, ${ }^{108}$ followed by Baldwin's mechanistic proposal. ${ }^{109}$ It has become a method of choice for the synthesis of cis-

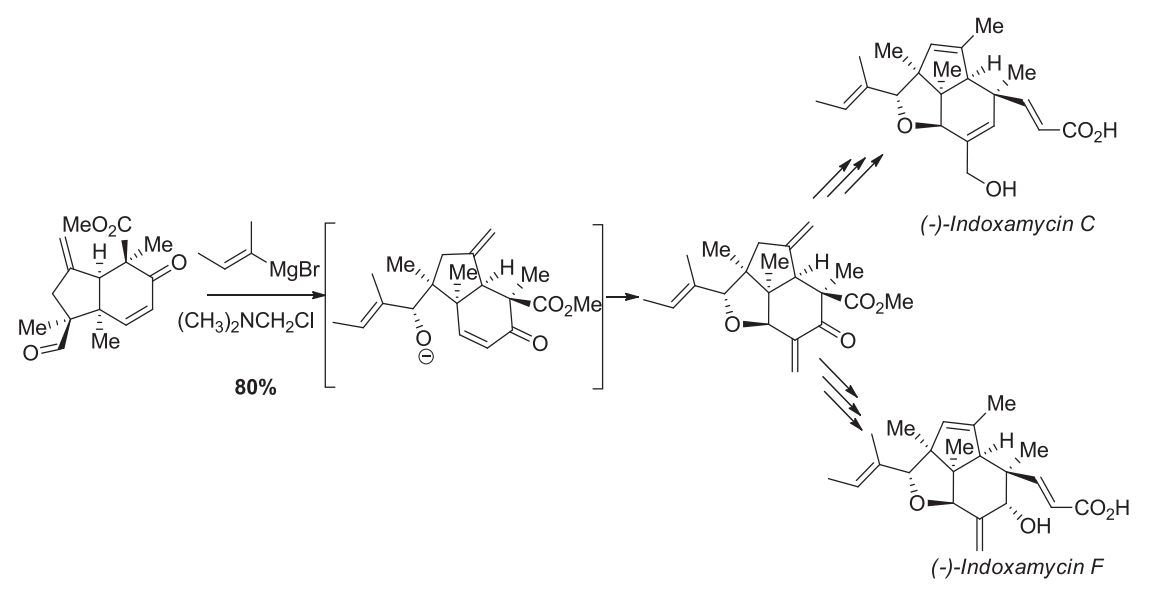

Scheme 32. 1,2-Addition/oxa-Michael/methylenation reaction. 


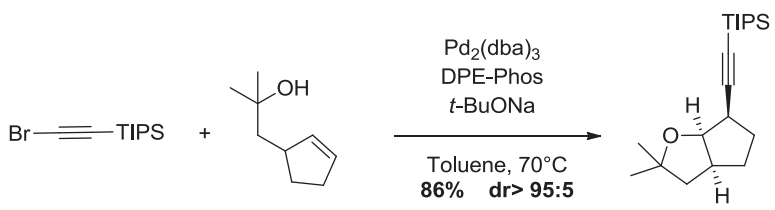

Scheme 33. Palladium-catalyzed coupling for the synthesis of THF.

2,5-substituted THF. ${ }^{110,111}$ Many advances in Os-mediated oxidative cyclization have been proposed and reviewed by the team of Donohoe. ${ }^{112}$ Among other methods recently published, we highlight the one proposed by Takenaka et al. where the oxidative cyclization of homoallylic alcohols is achieved by palladium, using $\mathrm{PhI}(\mathrm{OAc})_{2}$ as a reoxidant (Scheme 34$){ }^{113}$ In this case, good enantiomeric excess is obtained thanks to a spirobis-oxazoline ligand but no indications are given regarding the major enantiomer. A similar method had previously been published by the team of Sanford, also based on a $\mathrm{Pd}^{\mathrm{II}} / \mathrm{Pd}^{\mathrm{IV}}$ system, to allow the formation of THF with a phthalimide substituent in position 3 instead of the acetate, although with no enantiocontrol. ${ }^{114}$

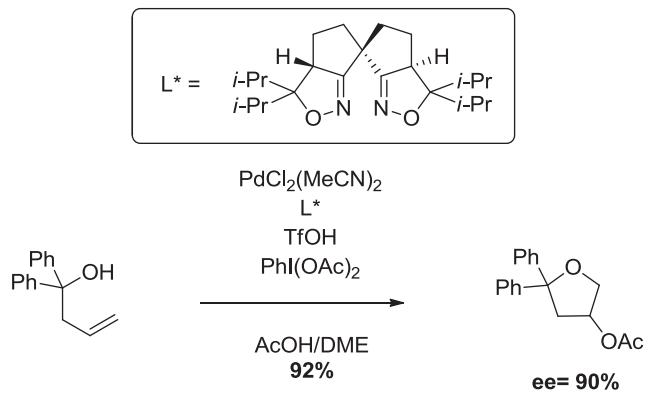

Scheme 34. Palladium-catalyzed oxidative cyclization.

The work of Donohoe was successfully applied by his group for the total synthesis of $(+)$-Sylvaticin and $(+)$-cis-Sylvaticin, ${ }^{115}$ Neodysiherbaine $A,{ }^{116}$ and for the synthesis of Pectenotoxin- $4 A B C$ spiroketal ring. ${ }^{117}$ The catalytic system employed for the three syntheses was: $\mathrm{K}_{2}\left[\mathrm{OsO}_{2}(\mathrm{OH})_{4}\right]$ with pyridine $N$-oxide and copper or zinc triflates. The last synthesis realized is a nice example of the osmium-mediated cyclization in cascade (Scheme 35).
Other oxidants were also employed to induce cyclization such as manganese $\left(\mathrm{KMnO}_{4}, \mathrm{NaMnO}_{4}\right.$ or $\left.\mathrm{MnO}_{2}\right)$. To our knowledge, four syntheses were performed by using those oxidants. In 2008, the team of Brown used potassium permanganate to achieve the tetrahydrofuran synthesis of cis-Sylvaticin and Membrarollin. ${ }^{118,119}$ Later on, the same team changed for the corresponding sodium counterion for the synthesis of trans- $(+)$-Linalool oxide. ${ }^{120}$ Manganese oxide was more recently used by the group of Vanderwal for the synthesis of Kalihinol B. ${ }^{121}$ Finally, oxone was also employed as oxidant by the group of Kang for the synthesis of (-)-Dysiherbaine. ${ }^{12}$

The use of these oxidants was compatible with several other groups, such as esters (Ac, Piv), ethers (Bn, PMB), carbonate (Boc), silyl ether (TBS, TBDPS), and acetonide.

Another nice example of the many options offered for the preparation of THF was presented by Fürstner and co-workers for the synthesis of Amphidinolide C and F. ${ }^{99,100}$ Actually, the authors used a TBAF-mediated hydroalkoxylation for the synthesis of the fragment $\mathrm{C} 16-\mathrm{C} 24$, and for the synthesis of $\mathrm{C} 1-\mathrm{C} 9$ fragment, a cobalt catalyzed oxidative cyclization using $\left(\mathrm{Co}(\mathrm{nmp})_{2}\right)$ catalyst (Scheme 36). Finally, the same catalytic system was employed by the team of Dias for the synthesis of (-)-Goniotrionin. ${ }^{123}$

\subsection{Miscellaneous}

Some recent strategies for the synthesis of oxolane structures involve a radical mechanism, such as the recent report by Fries et al., in which the THF is formed by a Co-catalyzed radical cyclization of a dihomo-allylic alcohol with a radical-trapping partner such as an $\alpha, \beta$-unsaturated ketone, ester or cyanide (Scheme 37).124 This method allows the formation of di- and tri-substituted THF with excellent trans-2,5-selectivity, and even bis-tetrahydrofurans, although in poor yield.

Recently, a carboetherification method was reported by the group of Chemler, leading to the formation of tricycle including a THF ring in good to excellent yield, probably through a radical intermediate. $^{125}$ The reaction is catalyzed by copper and a bisoxazoline ligand, and also needs 1 equiv of base and 3 equiv of $\mathrm{MnO}_{2}$ as an oxidant. Although initial results of enantioselectivity are described, the level of enantiocontrol remains moderate for now.

$\mathrm{C}-\mathrm{H}$ functionalization strategies can also be employed to synthesize THF rings. Recently, the group of Dong developed a THF synthesis, by oxime-directed $\mathrm{C}-\mathrm{H}$ activation of a methyl group,
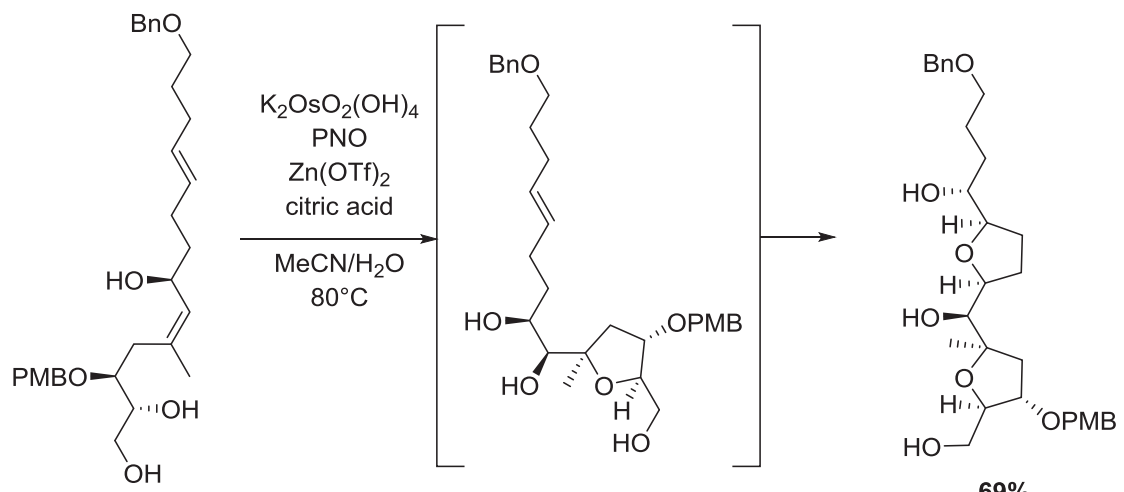

Scheme 35. Oxidative cyclization in cascade catalyzed by osmium. 


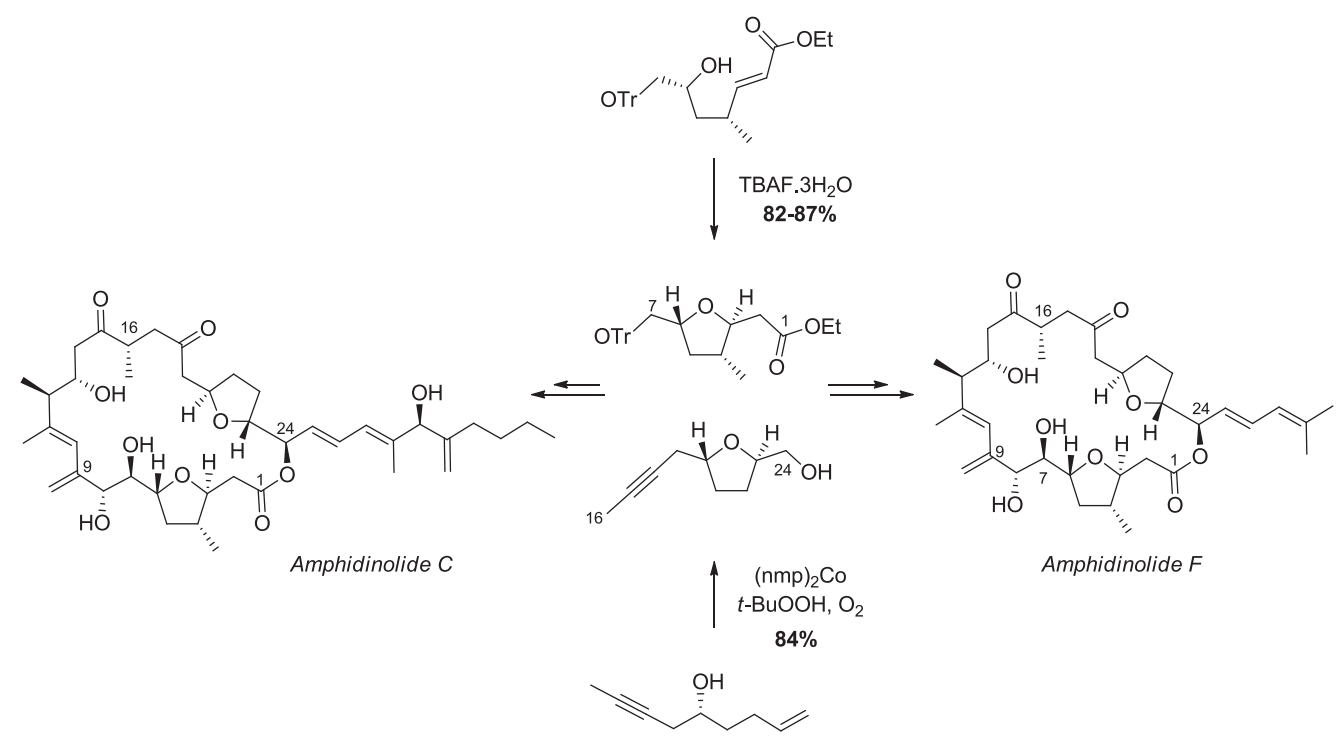

Scheme 36. Total synthesis of Amphidinolides C and F.

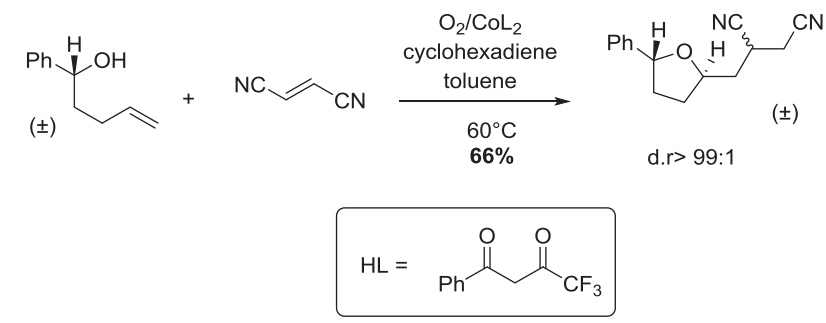

Scheme 37. Synthesis of functionalized THF by aerobic oxidation-radical cascade.

and further cyclization involving a primary, secondary or tertiary alcohol (Scheme 38). ${ }^{126}$ The process is catalyzed by $\mathrm{Pd}(\mathrm{OAc})_{2}$, and used $\mathrm{PhI}(\mathrm{OAc})_{2}$ as an oxidant. The oxime directing group can then be removed to get the interesting 3-hydroxy-THF motif in good yield. triethylsilane. $^{128}$ The key isomerization was notably mediated by ruthenium-catalysis.

Finally, the team of Lumb accomplished the synthesis of $( \pm)$-Tanegool and $( \pm)$-Pinoresinol, two lignan natural products, with the furanic core formation based on an oxidative opening of diarylcyclobutan diols as the key step. ${ }^{129}( \pm)$-Tanegool was synthesized in the presence of phenyliodine(III) diacetate (PIDA) in $40 \%$ yield as a single diastereomer (Scheme 39). Phenol oxidation by PIDA generated an oxonium ion, which induced a fragmentation of the cyclobutane followed by 5-exo-trig cyclization giving the furanic core. The use of $\mathrm{FeCl}_{3} \cdot 6 \mathrm{H}_{2} \mathrm{O}$ as alternative oneelectron oxidant afforded the desired product in 59\% yield along with the epimer in position 2 in $14 \%$ yield. The authors employed this second method to perform the synthesis of ( \pm )-Pinoresinol.

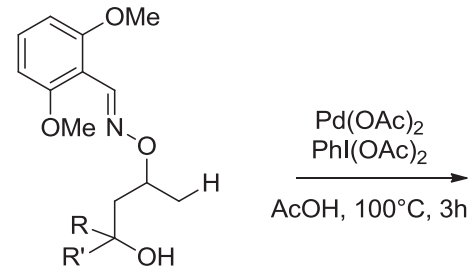

$R, R^{\prime}=H$, Alk, Ar

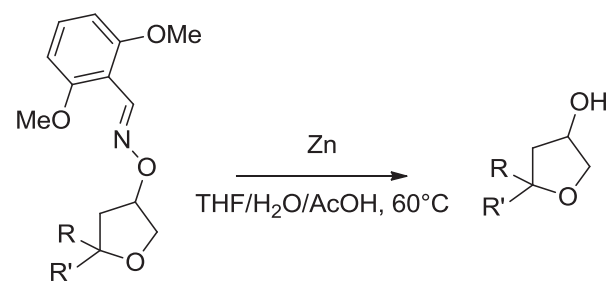

$19-86 \%$

Scheme 38. THF synthesis by $\mathrm{C}-\mathrm{H}$ activation.

THF moieties can also be obtained by allylic alcohol transposition followed by oxonium trapping with a nucleophile, as described by the team of Floreancig. ${ }^{127}$ However, only the formation of tetrahydropyranes leads to good diastereoselectivity using this approach.

Additionally, Fehr et al. described a method for the formation of trans-THF based on the isomerization of 2-butene-1,4-diols, to form a lactol intermediate which is then reduced by

\section{THF synthesis by $\mathrm{C}-\mathrm{C}$ bond formation}

\subsection{Cycloisomerization reactions}

Cycloisomerization reactions are known to allow the formation of 3,4-substituted THF structures from acyclic ethers. ${ }^{130}$ Recently, Evans et al. developed a rhodium-catalyzed cycloisomerization reaction of alkenylidene cyclopropanes, leading to 1,5-diene 


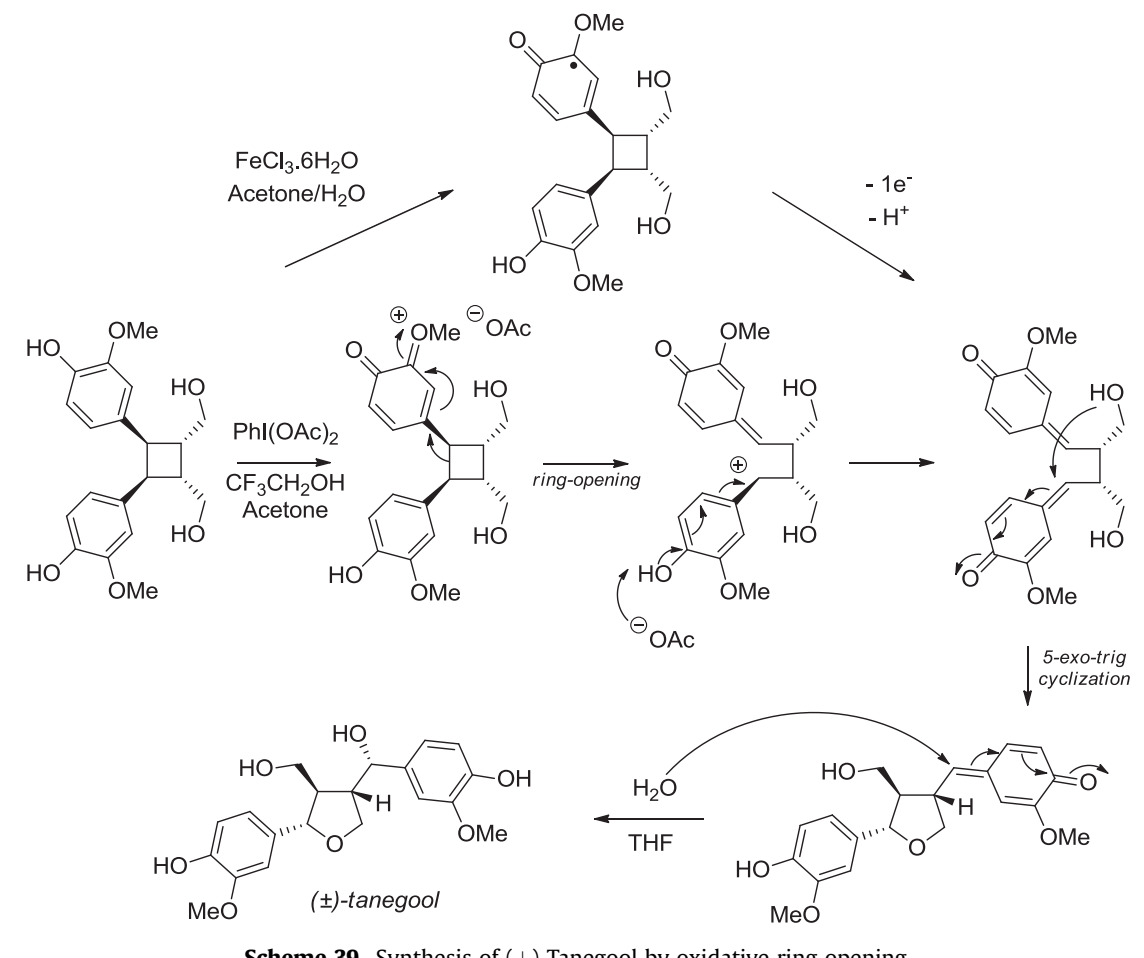

Scheme 39. Synthesis of $( \pm)$-Tanegool by oxidative ring opening.

structures, contrary to most cycloisomerization reactions that lead to 1,4-diene structures. ${ }^{131}$ Furthermore, this process shows very good cis-3,4-diastereoselectivity on the THF (Scheme 40).

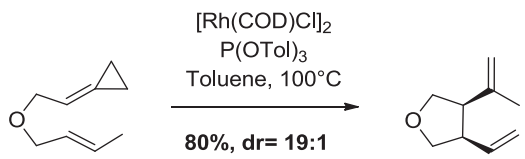

Scheme 40. Rh-catalyzed cycloisomerization of alkylidene cyclopropanes.

Apart from this methodology, recent advances in cycloisomerization-mediated formation of THF deal mainly with cycloisomerization sequences in tandem with other reactions, such as Wittig ${ }^{132}$ or Pd-catalyzed couplings. ${ }^{133}$

To the best of our knowledge, there is to date no use of this method in total synthesis.

\subsection{Radical processes}

The ability of titanium(III) to induce radical processes has been recently applied by the groups of Roy and Huang to the synthesis of THF structures. ${ }^{134,135}$ The method of Huang and co-workers is based on the reductive opening of an epoxide, followed by cyclization of the radical onto an allene. This method gives good yield but moderate diastereoselectivity. On the other hand, the method of Roy and co-workers allows synthesis of 2,3,4-trisubstituted THF bearing an electron-withdrawing group and a homobenzylic substituent in position 3, with complete diastereoselectivity (Scheme 41). The group of Medeiros described a similar radical cyclization, in which the radical is generated from a halide by the action of an electrogenerated $\mathrm{Ni}(\mathrm{I})$-tetramethylcyclam. ${ }^{136}$ Alkyl zinc reagents can also be used to realize the same kind of cascade cyclization, as showed by the group of Pérez-Luna. ${ }^{137}$

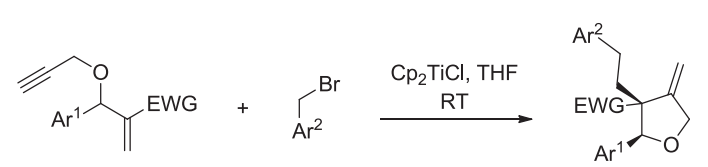

Scheme 41. Ti(III)-triggered radical cyclization into THF.

A radical cyclization into THF can also be achieved starting from a hydrogen atom transfer (HAT), as described by the group of Norton. ${ }^{138}$ The 2,3-disubstituted THF are formed by treatment of a vinyl ether with vanadium-hydride to form the stabilized radical that will cyclize onto a remote olefin. Interestingly, using different metal-hydride species, the HAT can be achieved selectively on the remote olefin, to reduce it without affecting the vinyl ether. Another HAT-mediated THF synthesis was also described, in which the radical cascade is initiated by the radical cleavage of an $N$-alkoxyphthalimide, followed by a 1,5-HAT to form the stabilized radical that will cyclize on a remote olefin. ${ }^{139}$ This last reaction gives THF with $n$-propanol substituent in position 2 and a radical-stabilizing group in position 3, in moderate to good yield.

Radical cyclization processes are regularly applied in total synthesis. Since 2006, four syntheses were employing radical cyclization in order to prepare tetrahydrofuran. Various radical systems were used such as $\mathrm{Bu}_{3} \mathrm{SnH}$ or (TMS) ${ }_{3} \mathrm{SiH}$ with $\mathrm{AIBN}$ or $\mathrm{Et}_{3} \mathrm{~B}$ as radical initiators.

In 2006, Lee and co-workers described the total synthesis of (-)-Amphidinolide E. ${ }^{140}$ The cis-2,5-disubstituted furan ring of Amphidinolide $\mathrm{E}$ was obtained by an intramolecular radical cyclization between an iodide moiety and an $\alpha, \beta$-unsaturated ester in $92 \%$ yield, thanks to (TMS) ${ }_{3} \mathrm{SiH} / \mathrm{Et}_{3} \mathrm{~B}$ system at $-20{ }^{\circ} \mathrm{C}$. The same radical initiator $\left(\mathrm{Et}_{3} \mathrm{~B}\right)$ was used in combination with $\mathrm{Bu}_{3} \mathrm{SnH}$ by the group of Lee for the total synthesis of cis-tetrahydrofuran skeleton of Amphidinolide, ${ }^{141}$ where the radical process proceeds through a reaction between a terminal alkyne and an $\alpha, \beta$-unsaturated ester. 
Triethylborane initiator was tested by the group of Landais during the synthesis of furan core of gymnodimine, albeit with a poor conversion. ${ }^{142} \mathrm{Et}_{3} \mathrm{~B}$ was then replaced by AIBN and the reaction between bromide and the terminal olefin proceeded smoothly, in good yields (63\% and $83 \%$ ) and diastereomeric ratio (98:2) depending on the substrate (Scheme 42).

\subsection{Miscellaneous}

The synthesis of oxolanes from acyclic ethers can be extended to most of the classic $\mathrm{C}-\mathrm{C}$ bond formation strategies. Among them, we can highlight the Hosomi-Sakurai reaction, recently applied by Cox and co-workers to the synthesis of 2,3,4-trisubstituted THF with
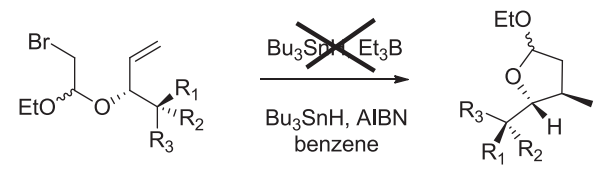

$\mathrm{R}_{1}=\mathrm{H}, \mathrm{R}_{2}=\mathrm{CH}_{3}, \mathrm{R}_{3}=$ OTBDMS, $\mathbf{8 3} \%, \mathrm{dr}=\mathbf{9 8 : 2}$
$\mathrm{R}_{1}=\mathrm{CH}_{3}, \mathrm{R}_{2}=\mathrm{H}, \mathrm{R}_{3}=\mathrm{CH}_{2} \mathrm{OBn}, \mathbf{6 3} \%, \mathrm{dr}=\mathbf{9 8 : 2}$

Scheme 42. Radical cyclization for the synthesis of gymnodimine THF ring.

Additionally, $\mathrm{Bu}_{3} \mathrm{SnH} / \mathrm{AIBN}$ system was used by Donner for the formal syntheses of $(+)$-Secosyrin and Longianone. ${ }^{143}$ The intramolecular radical reaction proceeded between the aldehyde and an olefin bearing an ester group to form the furan rings. It should be mentioned that two substituted furans were observed in modest yields, and that only the furan where the hydroxyl and the methyl ester are syn, completed a lactonization reaction (Scheme 43). moderate to good diastereoselectivities. ${ }^{144}$ Still starting from an acyclic ether, the $\mathrm{C}-\mathrm{C}$ bond can also be formed by a domino Heck-Suzuki reaction, as shown by Braun et al., ${ }^{145}$ by reaction of a carbene with a benzylic ether, ${ }^{146}$ following an indium-catalyzed hydrative cyclization of diyne. ${ }^{147}$

Another strategy developed by Rovis and co-workers involves a cyclic acetal, which is activated by a Lewis acid to perform a ring

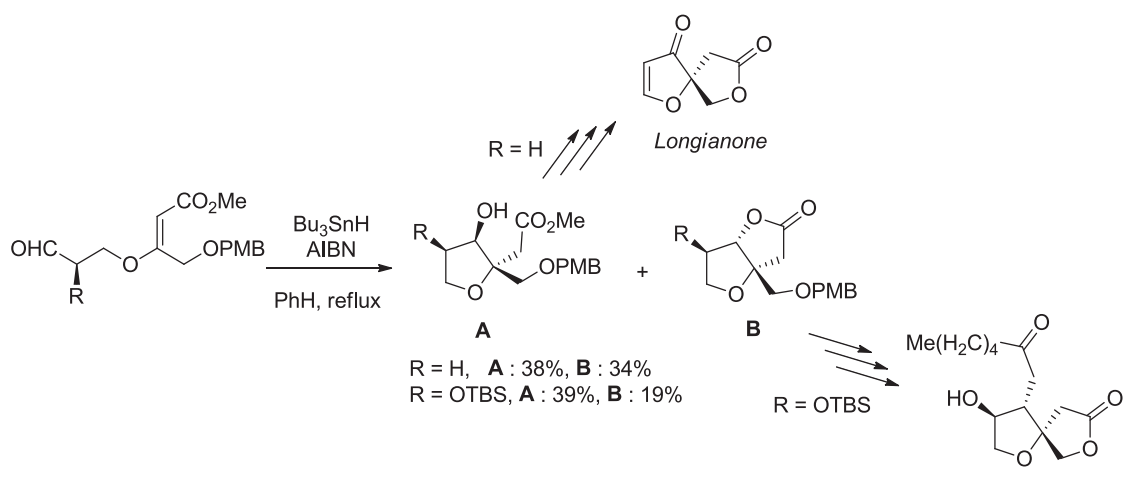

(+)-Secosyrin

Scheme 43. Furan ring formation of Longianone and (+)-Secosyrin.

Also of a note is that some protecting groups were tolerated during the radical process, such as benzyl, TBS, TIPS or TPDPS, PMB, and MOM groups. contraction by Mukaiyama-aldol reaction leading to 2,3,4trisubstituted THF. ${ }^{148}$ Notably, the choice of the Lewis acid can lead to two different diastereoselectivities. A similar approach has also been exploited by Friestad and co-workers, but with an external nucleophile (Scheme 44). ${ }^{149}$

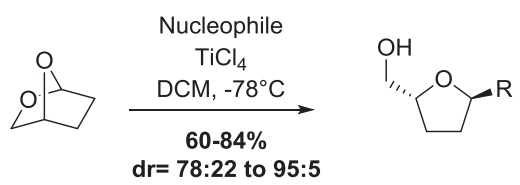

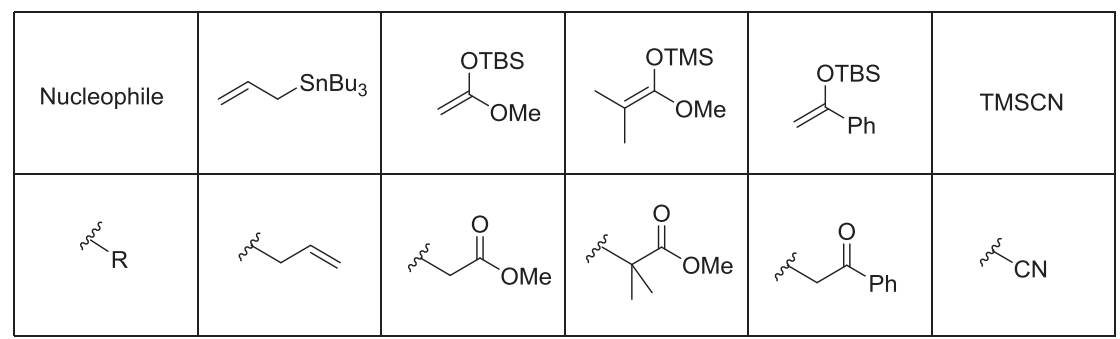

Scheme 44. THF synthesis by acetal reduction. 
Finally, the THF ring can be formed by a two-component reaction, either by a [4+2] cycloaddition-ring opening metathesis sequence always with a cis-2,5-diastereoselectivity, ${ }^{150,151}$ or by a $\mathrm{S}_{\mathrm{N}} 2$ alkylation-Michael addition sequence, using an activated methylene group as a partner of the functionalized ether. ${ }^{152}$

From all the recent methodologies presented above, there is to date no recent application in total synthesis. Nonetheless, several examples of cycloaddition were reported in the literature.

The team of Ding worked on the synthesis of (rac)-Steenkrotin $A,{ }^{153}$ where the tetrahydrofuran was synthesized starting from an aldehyde and an olefin, in an intramolecular fashion using HF pyridine reagent.

The work of $\mathrm{Pu}$ toward the synthesis of Mangicol $\mathrm{A}$, is also a recent example using a domino Pauson-Khand/Diels-Alder cycloaddition process, catalyzed by $\left[\mathrm{RhCl}(\mathrm{CO})_{2}\right]_{2}$, under carbon monoxide pressure. ${ }^{154}$ The work reported in this article was essentially to develop the cycloaddition processes for future application in total synthesis, and tetrahydrofuran rings were obtained by cycloisomerization in moderate to good yields (44-71\%) and good enantiomeric excess (72-94\%). Additionally, some examples report the creation of four cycles and three or four stereogenic centers (Scheme 45).

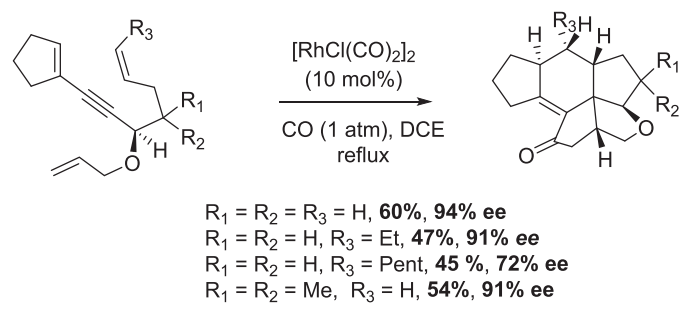

Scheme 45. Domino Pauson-Khand/Diels-Alder cycloaddition for the formation of pentacyclic molecules.

Then, two other recent examples of cycloadditions were reported, in 2012 and 2014 by the groups of Coquerel/Rodriguez ${ }^{155}$ and Gong/Yang, ${ }^{156,157}$ respectively. A regioselective $(5+2)$ cycloaddition process was used for the formation of polyether furanic cores starting from terminal alkenes and the 3-oxido-pyrilium betaine prepared in situ. Four olefins were studied, bearing a phenyl group or ether groups (OEt, OBn) in 31\%-67\% yield to obtain cis-2,3,5trisubstituted furans (Scheme 46). ${ }^{155}$

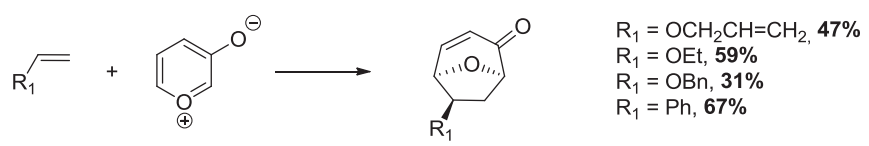

Scheme 46. Regioselective $(5+2)$ cycloadditions.

The team of Gong and Yang worked on the total synthesis of maoecrystal $\mathrm{V}$ and succeeded to produce the cis-furan ring using a rhodium ${ }^{\mathrm{II}}$ catalyzed $\mathrm{C}-\mathrm{O}$ insertion followed by an intramolecular Diel-Alder reaction. ${ }^{156}$ A mixture of endo and exo-compounds were obtained in addition with another regioisomer of the exo-product coming from previous step.
Additionally, one example of $\mathrm{C}-\mathrm{H}$ insertion was reported by the group of Zakarian for the obtention of the furan ring of Maoecrystal $\mathrm{V},{ }^{158}$ where the furan was obtained by a rhodium catalyzed reaction on an $\alpha$-diazoester (Scheme 47).

\section{THF synthesis by simultaneous $\mathrm{C}-\mathrm{O}$ and $\mathrm{C}-\mathrm{C}$ bond formations}

\subsection{Cycloadditions}

4.1.1. (3+2) Cycloadditions involving a cyclopropane. Polysubstituted THF structures can be synthesized in a diastereoselective fashion by cycloaddition between an aldehyde and a 1,3-dipole. ${ }^{159}$ Recently, a plethora of methods have been developed allowing the use of cyclopropane as 1,3-dipole equivalent. To allow the reactivity, the cyclopropane must be substituted by an electron-withdrawing group and/or an electron donating group. In most of the cases, the electron-withdrawing group comes from a malonate, while the electron-donating group can be a vinyl or an aryl, ${ }^{160}$ an amine ${ }^{161}$ or even a diene-iron complex. ${ }^{162}$ This reactivity is allowed by a Lewis acid activation, or by palladium catalysis. ${ }^{163,164}$ The oxolanes obtained usually display a good cis-2,5-stereochemistry. An enantioselective version of this transformation was proposed by the group of Johnson, by means of deracemization of the starting aryl or vinyl cyclopropane through a dynamic kinetic asymmetric transformation. ${ }^{165}$ In this case, the Lewis acid catalyst, helped by a chiral PyBOX ligand, promotes the cycloaddition of only one enantiomer of the cyclopropane, while the other one is racemized (Scheme 48). The cis-2,5-THF are obtained in good enantioselectivity and excellent diastereoselectivity. In the case of phthalimide-substituted cyclopropanes, the reaction can also be enantiospecific, ${ }^{166}$ and recently another dynamic kinetic asymmetric transformation was described by De Nanteuil et al. using these substrates and catalyzed by copper bisoxazoline salts. ${ }^{167}$ This last method led to the formation of various 2,3,5-trisubstituted THF in good to excellent yield (up to 97\%) and enantioselectivity (ee up to $92 \%$ ).

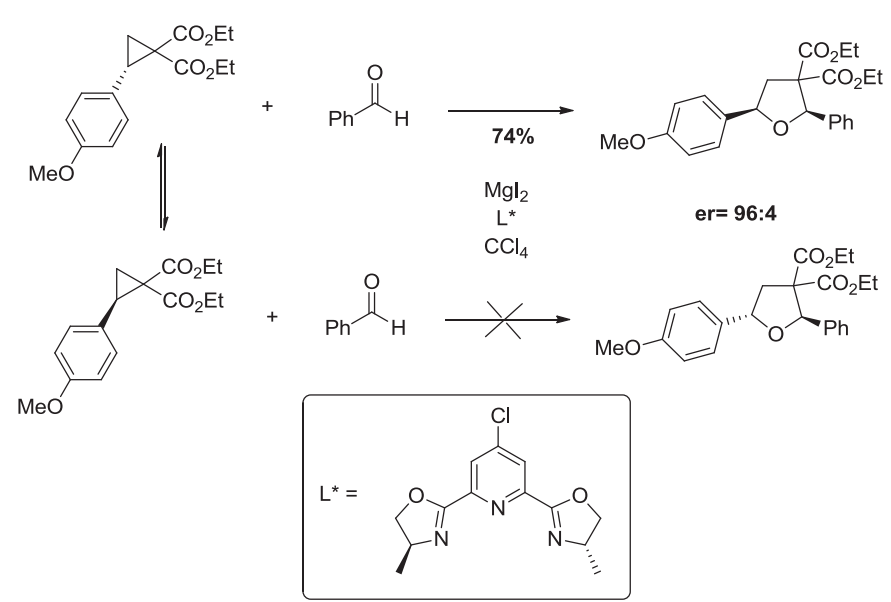

Scheme 48. Enantioselective synthesis of THF by deracemizing $(3+2)$ cycloaddition.

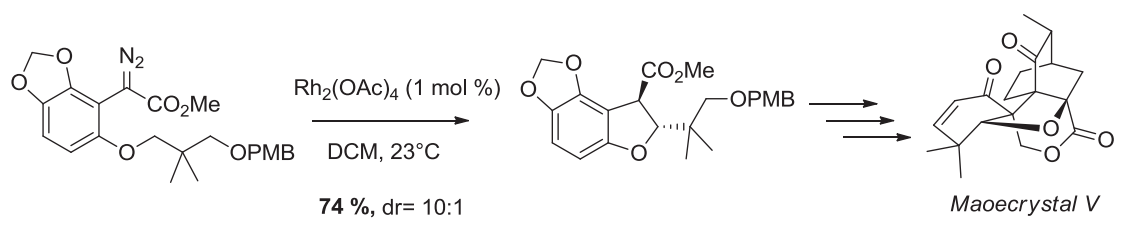

Scheme 47. $\mathrm{C}-\mathrm{H}$ insertion using rhodium acetate. 
$(3+2)$ Cycloadditions between cyclopropanes and aldehydes can also lead to trans-2,5-THF, as shown by Yang and co-workers. ${ }^{168}$ In their study, the authors show that in the case of 1,1,2,3tetrasubstituted cyclopropanes with a cis-2,3 configuration, the oxolanes obtained by cycloaddition display a cis-2,3 and trans-2,5 relative stereochemistry, when an electron-rich aldehyde is used (Scheme 49). Interestingly, the authors showed that when cyclopropanes with trans-2,3 configuration are used, the THF obtained display a mixture of trans-2,3 and cis-2,5 relative stereochemistry. ${ }^{169}$
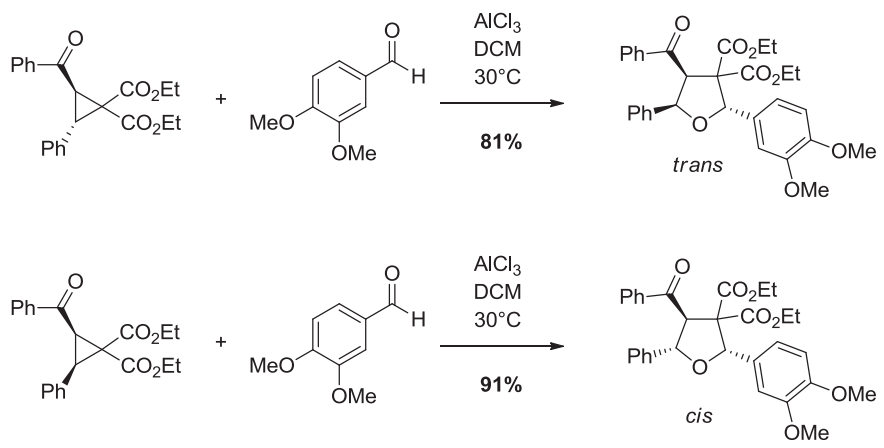

Scheme 49. THF synthesis from 1,1,2,3-tetrasubstituted cyclopropanes.

The reactivity of cyclopropanes can still be observed without the electron-withdrawing groups if there is a silane substituent as an electron-donating group. ${ }^{170}$ In this case, the resulting oxolanes display a trans-2,5 relative stereochemistry, and can be further functionalized, as valuable building blocks. ${ }^{171}$ Vinylidene cyclopropanes can also be used as a 1,3-dipole equivalent to synthesize THF, by cycloaddition with an aldehyde bearing an ester function in $\alpha$ position, as demonstrated by the work of Shi and co-workers. ${ }^{172}$ This method was later extended to other aldehydes by Huang and co-workers, ${ }^{173}$ to give an array of oxolanes that can be further modified. ${ }^{174}$

Despite the growing interest in cycloaddition reactions, there is to date no recent report of cycloadditions involving cyclopropanes in total or formal synthesis of natural products.

4.1.2. Other cycloadditions. Other cycloaddition methods can lead to oxolane structures. For example, $(3+2)$ cycloaddition between allylic or propargylic alcohols and electron-deficient olefins have been extensively studied in the past years. ${ }^{175}$ Recent methods allow this kind of reactivity by Lewis acid ${ }^{176,177}$ or Lewis base catalysis, ${ }^{178}$ by Brønsted base activation, ${ }^{179}$ or by photoredox catalysis (Scheme 50). ${ }^{180}$ These methods use only simple starting materials (allylic or propargylic alcohol and olefins), however the diastereoselectivities are usually moderate.

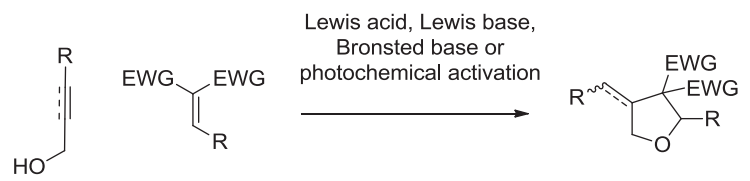

Scheme 50. General scheme of $(3+2)$ cycloaddition of allylic or propargylic alcohols with olefins.

Lewis base activation of allenoates is a well-known method to trigger cycloadditions, extensively studied since the first reports by the group of Lu. ${ }^{181}$ This reactivity could be transposed using various electrophiles, but in the case of aldehydes, the variety of different reactive pathways made the synthesis of THF tricky. Recently, Xu et al. developed a phosphine-catalyzed synthesis of oxolanes by activation of the $\gamma$-methyl group of the allenoate (Scheme 51). This reaction is limited to electron-poor aromatic aldehydes. ${ }^{182}$

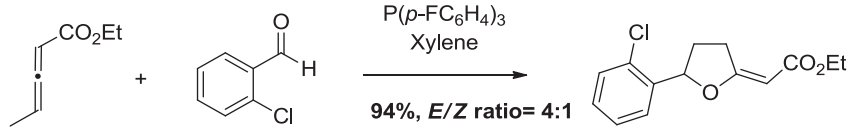

Scheme 51. $(3+2)$ cycloaddition of allenoates with aromatic aldehydes.

Allylsilanes are also good partners of aldehydes for $(3+2)$ cycloadditions. Thus, Angle et al. recently reported a cycloaddition of allylsilanes with $\alpha$-hydroxy aldehydes, leading to 2,3,5trisubstituted oxolanes in moderate yield and diastereoselectivity. ${ }^{183}$ This kind of Lewis acid-catalyzed transformation can also lead to a 1,2-silyl shift, along with the cycloaddition. ${ }^{184,185}$ Allyl-boranes can also react in a similar fashion with aldehydes, with the possibility of enantiocontrol using allyldiisopinocamphenylborane. ${ }^{186}$ The one-pot, three-step procedure involves an allylboration of the aldehyde, followed by a hydroboration and iodination to trigger the cyclization (Scheme 52). The corresponding 2,3-disubstituted THF are obtained in good yield and excellent enantioselectivity.

The synthesis of THF can also be achieved by rhodium-catalyzed $(4+1)$ cycloaddition between a homoallylic or homopropargylic alcohol and a diazo compound. Xu et al. employed this strategy in a two-step one-pot process, where the rhodium carbene first makes an ether intermediate, further cyclized through a basepromoted Michael addition. ${ }^{187}$ In this case, fully substituted THF are synthesized in good yield and excellent diastereoselectivities. However, the necessity of having aromatic substituents in positions 2 and 5 , a phenyl in position 3 and a phenone in position 4 narrows the scope of the reaction. In an extension of this work, the same group described a similar reaction yielding 2,2,3,3,5pentasubstituted-3-hydroxy-THF with a wider scope and in a one-pot process. ${ }^{188}$ In this last case, the partner of the diazo compound contains a ketone instead of the Michael olefin. Recently, a more direct method was developed by Urabe et al. (Scheme 53). ${ }^{189}$ In this case the ether formation is directly followed by a Lewis acid-catalyzed cyclization, yielding 2-methylene THF in very good yield, but moderate diastereoselectivity. The group of Mascarenas/Lopez also described a cascade cycloaddition leading to various sizes of oxa-bridged carbocycles, among which some THF were synthesized. This last method relies on the activation of allenamides by gold, which can then react with a carbonyl-tethered alkene. $^{190}$

Finally, epoxides can also be partners for cycloaddition leading to oxolanes. ${ }^{191,192}$ However, the methods are scarce and limited to a narrow family of substrates.

Despite the recent studies above-mentioned using cycloaddition reactions for the synthesis of tetrahydrofurans, to the best of our knowledge, there is no recent use of these methods in total synthesis. However, three examples of $(3+2)$ cycloaddition reactions were reported for the obtention of furan moiety of natural products. The teams of Sugimura and Panek performed $(3+2)$ cycloaddition reactions between aldehydes and olefins using Lewis acid $\left(\mathrm{BF}_{3} \cdot \mathrm{Et}_{2} \mathrm{O}\right)^{193}$ or Brønsted acid (PTSA) ${ }^{194}$ and produced cistetrahydrofurans of Plakortone $\mathrm{L}$ and (+)-Isatisine A, respectively. The group of Roush obtained a trans-tetrahydrofuran by using $\mathrm{SnCl}_{4}$ toward the synthesis of $\mathrm{C} 1-\mathrm{C} 9$ fragment of Amphidinolide C (Scheme 54). ${ }^{185}$ All tetrahydrofurans were obtained with good stereoselectivities $(\mathrm{dr} \geq 20 / 1)$.

During those annulations under acid conditions, several functional groups remained stable such as silyl ethers (TBS, TBDP), $\mathrm{CHSiMe}_{2} \mathrm{Ph}$, ethyl ester, and acetonide.

\subsection{Reactions involving an oxonium intermediate}

THF structures can be formed in an intermolecular fashion by Prins reactions and related methods. In this case, the starting 


$$
\left.\begin{array}{l}
\mathrm{R}^{1}, \mathrm{R}^{2}=\mathrm{H}, \mathrm{Me}, \mathrm{OMe} \\
\mathrm{R}^{3}=\mathrm{Alk}, \mathrm{Ar}
\end{array}\right]
$$

Scheme 52. Enantioselective THF synthesis by one-pot allylboration, hydroboration, and iodation.<smiles>[R]C#CC([R])([R])C([R])([R])O</smiles>

$\mathrm{R}=\mathrm{H}$, Alk $\mathrm{EWG}=\mathrm{COPh}, \mathrm{CO}_{2} \mathrm{Me}$

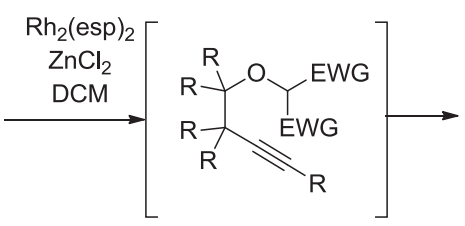<smiles>[R]C=C1C([R])([R])C([R])OC1([R])C([N+])([O-])[O-]</smiles>

Scheme 53. THF formation by (4+1) cycloaddition between a rhodium-carbene and a homopropargylic alcohol.

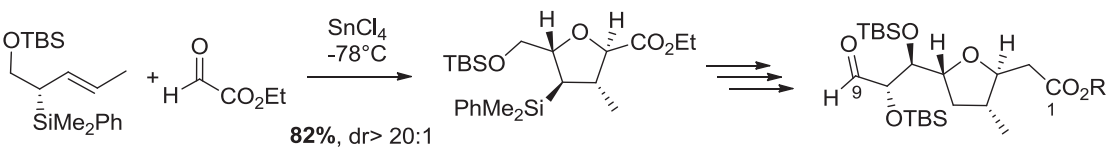

Scheme 54. Synthesis of trans-tetrahydrofuran of $\mathrm{C} 1-\mathrm{C} 9$ fragment of Amphidinolide $\mathrm{C}$ with $\mathrm{SnCl}_{4}$.

materials are a homoallylic or homopropargylic alcohol and an aldehyde. This kind of reaction needs Lewis acid activation to form the oxonium intermediate (Scheme 55). The $\pi$-system that will attack the oxonium intermediate can be an allylic stannane, as described by Kim et al., ${ }^{195}$ or an alkyne, in which case the vinyl cation can be trapped by a triflate counteranion, as described by Chavre et al. ${ }^{196}$ In both cases the reaction tolerates secondary alcohols and aryl as well as aliphatic aldehydes, in good yield and good cis-2,5 selectivity. A similar method was proposed by the group of Spivey when the nucleophile was a benzylic olefin, and the benzylic cation intermediate was trapped either by bromine or by an internal nucleophile such as a phenol. ${ }^{197}$ In this last case, fused THF-benzopyranes are obtained. Another possible nucleophile can be an enethiol-ether, as described by Reddy and co-workers. ${ }^{198}$ The thionium intermediate is then trapped by a second thiolate coming from a sacrificial equivalent of starting material. However, these last reactions are only described with primary alcohols.
Another strategy to prepare oxolanes via oxonium intermediates involves the formation of a rhodium-carbene from a diazo compound. Coupling with an aldehyde leads to a 1,3-dipole intermediate that can react with a polarized olefin in a threecomponent reaction yielding 2,3,5-trisubstituted THF. ${ }^{199}$ The scope of this reaction is limited to aromatic aldehydes, therefore the oxolanes obtained using this method have an aromatic substituent in position 2, and an electron-withdrawing group in positions 3 and 5 (Scheme 56). Further, diastereocontrol can be obtained using a chiral oxazolidinone auxiliary as the electron withdrawing group. ${ }^{200}$

Finally, Hosomi-Sakurai reaction of bis-allylsilanes using 2 equiv of aldehyde was described by Roux et al. to yield 2,3,5trisubsituted THF in good yields, in which substituent 2 and 5 are identical and coming from the same aldehyde. ${ }^{201}$ A two-step process using unsymmetrical bis-allylsilanes was developed by Malkov et al. to allow access to 2,3,5-trisubstituted THF in which

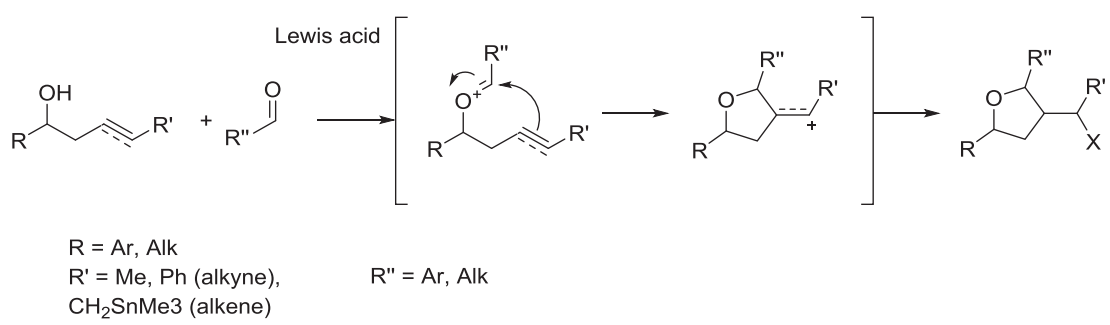

Scheme 55. General scheme of THF synthesis approach by Prins or related reactions. 


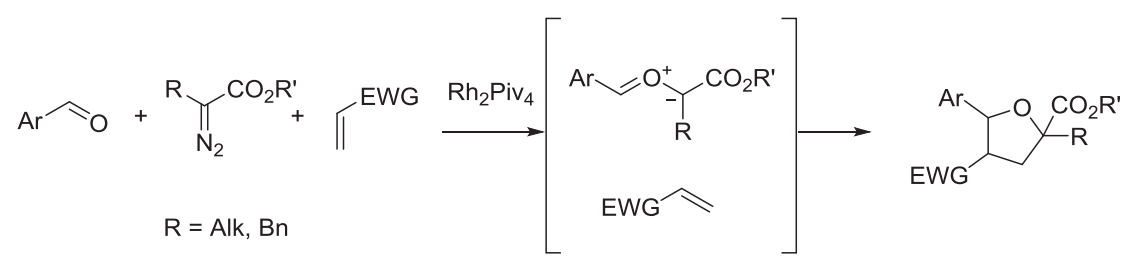

Scheme 56. THF synthesis by a three-component reaction involving a diazo compound.

substituents 2 and 5 are different. ${ }^{202}$ In this case, the first allylation is catalyzed by a chiral $\mathrm{N}$-oxide Lewis base such as Quinox or Methox.

Cyclizations using oxonium intermediates are abundant in synthesis and have the advantage of being stereoselective. The recent methods described in this manuscript have not yet been applied towards natural product synthesis. However, since the review of Wolfe and Hay a few groups reported oxonium mediated cyclizations in synthesis through the formation of lactones or hemiketals such as the groups of Forsyth ${ }^{203}$ and Song ${ }^{204}$ for the synthesis of fragment $\mathrm{C} 1-\mathrm{C} 21$ of Azaspiracids 1 and 3 after a Kishi reductive procedure. In addition, the team of Nakada used a Hosomi-Sakurai reaction in order to produce the desired spirocyclic ring of the (+)-Ophiobolin A using $\mathrm{BF}_{3} \cdot \mathrm{Et}_{2} \mathrm{O}$ (Scheme 57). ${ }^{205}$

Finally, an acidic treatment of a $\gamma$-hydroxyketone in which the hydroxyl moiety was protected as trimethylsilyl ether allowed the formation of the furan ring after deprotection of the TMS group and cyclization through oxonium intermediate (Scheme 58). This procedure permitted Fujiwara's group to access Pectenotoxin-2 furan core. $^{206}$

\subsection{Other annulation reactions}

THF can be synthesized using 1,3-dipoles and aldehydes or ketones. Recently, Trost and co-workers coupled trimethylenemethane with aromatic aldehydes and ketones in a palladium catalyzed process leading to methylene tetrahydrofuran structures in good yield (Scheme 59). ${ }^{207,208}$ Excellent enantioselectivity could be obtained using chiral phosphoramidite ligands. Other possible 1,3-dipole equivalents are 3-chloropropylphenylsulfones or sulfoxides, activated by a Brønsted base, used by the group of Mąkosza to form trans-2,3 disubstituted oxolanes. ${ }^{209,210}$

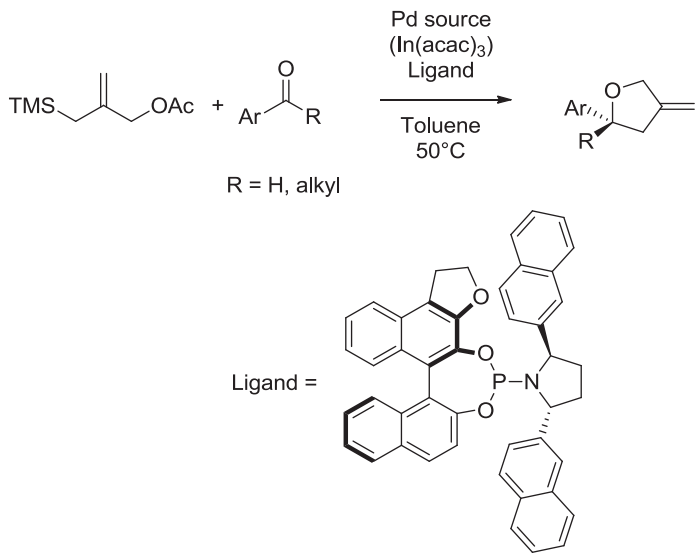

Scheme 59. THF synthesis using trimethylenemethane.

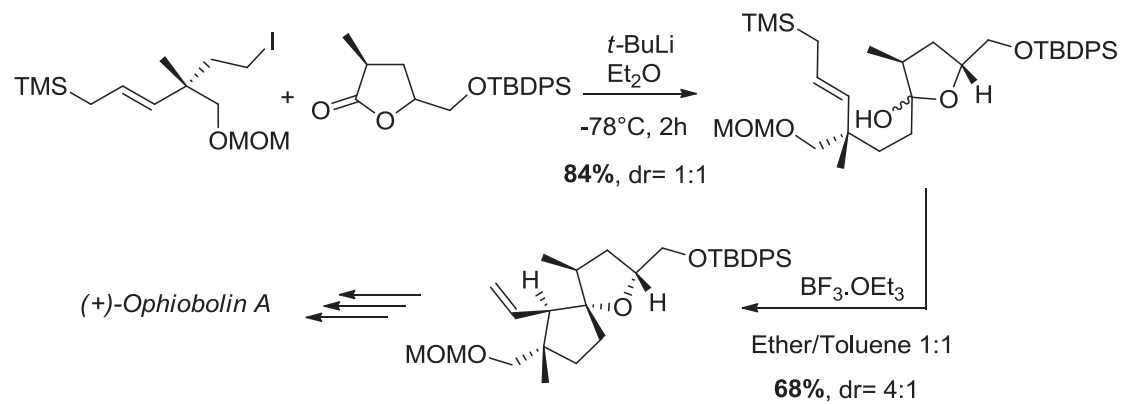

Scheme 57. Synthesis of spirocyclic ring of the $(+)$-Ophiobolin A.

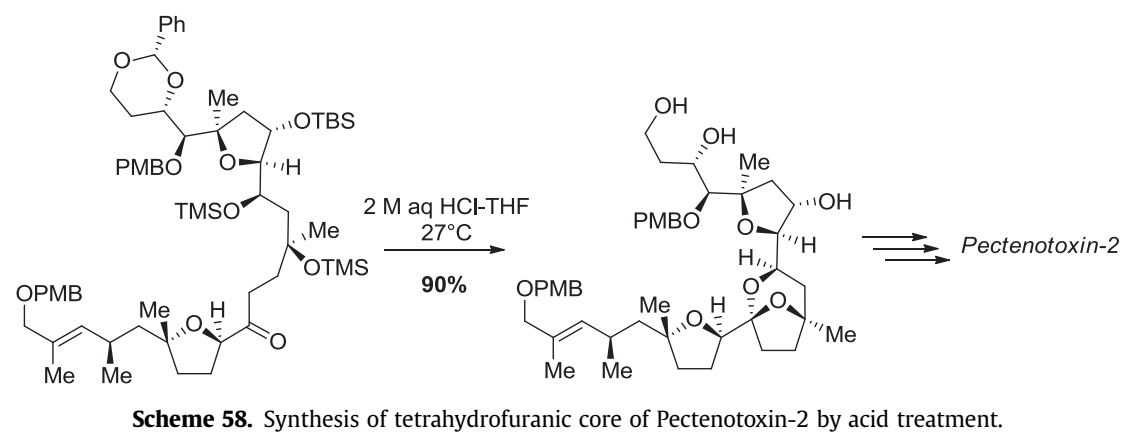




\section{Conclusion}

Since the most recent comprehensive review of tetrahydrofuran formation, ${ }^{5}$ several methods have been developed and employed as central strategic steps in the total synthesis of a wide variety of mono or polycyclic molecules. These methods provide the organic and medicinal chemist with a wide variety of synthetic opportunities: $\mathrm{C}-\mathrm{O}$ or $\mathrm{C}-\mathrm{C}$ bond forming reactions as well as simultaneous formation of $\mathrm{C}-\mathrm{O}$ and $\mathrm{C}-\mathrm{C}$ bonds. Some methods may even be orchestrated in cascades to enhance the synthesis. In this review, we have presented these new approaches, especially those presenting opportunity for enantioselectivity. Where the THF formation is not interestingly stereocontroled, chiral centers may be controlled upstream using enantioselective reactions (e.g., Sharpless epoxidation, dihydroxylation etc.). As demonstrated by this review, the range of approaches available for THF preparation continues to grow with the development of new processes and improvement of older ones. The research in this area should continue and will result in new efficiencies in total synthesis.

\section{Acknowledgements}

The authors gratefully thank the University of Montpellier for the PhD fellowships of Claire Cuyamendous and Aurélien de la Torre. The authors gratefully thank Dr. Paul Teesdale-Spittle for his careful and helpful proofreading.

\section{References and notes}

1. Lorente, A.; Lamariano-Merketegi, J.; Albericio, F.; Álvarez, M. Chem. Rev. 2013 113, 4567-4610.

2. Faul, M. M.; Huff, B. E. Chem. Rev. 2000, 100, 2407-2474.

3. Li, N.: Shi, Z.; Tang, Y.; Chen, J.; Li, X. Beilstein J. Org. Chem. 2008, 4.

4. Jahn, U.; Galano, J.-M.; Durand, T. Angew. Chem., Int. Ed. 2008, 47, 5894-5955.

5. Wolfe, J. P.; Hay, M. B. Tetrahedron 2007, 63, 261-290.

6. Fukuyama, T.; Vranesic, B.; Negri, D. P.; Kishi, Y. Tetrahedron Lett. 1978, 19, 2741-2744.

7. Pfenninger, A. Synthesis 1986, 1986, 89-116.

8. Katsuki, T. Synlett 2003, 0281-0297.

9. Frohn, M.; Shi, Y. Synthesis 2000, 2000, 1979-2000.

10. Cane, D. E.; Celmer, W. D.; Westley, J. W. J. Am. Chem. Soc. 1983, 105, 3594-3600.

11. Vilotijevic, I.; Jamison, T. F. Angew. Chem., Int. Ed. 2009, 48, 5250-5281.

12. Marshall, J. A.; Mikowski, A. M. Org. Lett. 2006, 8, 4375-4378.

13. Marshall, J. A.; Hann, R. K. J. Org. Chem. 2008, 73, 6753-6757.

14. Florence, G. J.; Cadou, R. Tetrahedron Lett. 2008, 49, 6784-6786.

15. Veidenberg, I.; Toom, L.; Villo, P.; Vares, L. Tetrahedron Lett. 2014, 55, 3569-3571.

16. Ueberbacher, B. T.; Oberdorfer, G.; Gruber, K.; Faber, K. ChemBioChem 2009, 10, 1697-1704.

17. Hu, L.; Lu, X.; Deng, L. J. Am. Chem. Soc. 2015, 137, 8400-8403.

18. Blanc, A.; Toste, F. D. Angew. Chem., Int. Ed. 2006, 45, 2096-2099.

19. Aho, J. E.; Salomäki, E.; Rissanen, K.; Pihko, P. M. Org. Lett. 2008, 10, 4179-4182.

20. Chen, Y.: Jin, J.: Wu, J.: Dai, W.-M. Synlett 2006, 1177-1180.

21. Morimoto, Y.; Yata, H.; Nishikawa, Y. Angew. Chem., Int. Ed. 2007, 46 6481-6484.

22. Sabitha, G.; Sandeep, A.; Rao, A. S.; Yadav, J. S. Eur. J. Org. Chem. 2013, 2013, 6702-6709.

23. Ding, X.-B.; Furkert, D. P.; Capon, R. J.; Brimble, M. A. Org. Lett. 2014, 16, $378-381$.

24. Schmidt, J.; Khalil, Z.; Capon, R. J.; Stark, C. B. W. Beilstein J. Org. Chem. 2014, 10, $1228-1232$.

25. Gille, A.; Hiersemann, M. Org. Lett. 2010, 12, 5258-5261.

26. Shepherd, D. J.; Broadwith, P. A.; Dyson, B. S.; Paton, R. S.; Burton, J. W. Chem. -Eur J. 2013, 19, 12644-12648.

27. Rodríguez-López, J.; Pinacho Crisóstomo, F.; Ortega, N.; López-Rodríguez, M.; Martín, V. S.; Martín, T. Angew. Chem., Int. Ed. 2013, 52, 3659-3662.

28. Morimoto, Y.; Okita, T.; Takaishi, M.; Tanaka, T. Angew. Chem., Int. Ed. 2007, 46 $1132-1135$.

29. Morimoto, Y.; Okita, T.; Kambara, H. Angew. Chem., Int. Ed. 2009, 48, 2538-2541.

30. Cuyamendous, C.; Leung, K. S.; Durand, T.; Lee, J. C.-Y.; Oger, C.; Galano, J.-M Chem. Commun. 2015, 15696-15699.

31. Taber, D. F.; Pan, Y.; Zhao, X. J. Org. Chem. 2004, 69, 7234-7240.

32. Taber, D. F.; Zhang, Z. J. Org. Chem. 2006, 71, 926-933.

33. Taber, D. F.; Gu, P.; Li, R. J. Org. Chem. 2009, 74, 5516-5522.

34. Jeker, O. F.; Carreira, E. M. Angew. Chem., Int. Ed. 2012, 51, 3474-3477.
35. Helmboldt, H.; Aho, J. E.; Pihko, P. M. Org. Lett. 2008, 10, 4183-4185. 36. Kang, S. H.; Lee, S. B.; Park, C. M. J. Am. Chem. Soc. 2003, 125, 15748-15749. 37. Kang, S. H.; Park, C. M.; Lee, S. B.; Kim, M. Synlett 2004, 1279-1281.

38. Kwon, H. Y.; Park, C. M.; Lee, S. B.; Youn, J.-H.; Kang, S. H. Chem.-Eur. J. 2008, $14,1023-1028$

39. Neverov, A. A.: Brown, R. S. J. Org. Chem. 1996, 61, 962-968.

40. Ramos, J. C.; Brovetto, M.; Seoane, G. A. Org. Lett. 2013, 15, 1982-1985.

41. Fujioka, H.; Maehata, R.; Wakamatsu, S.; Nakahara, K.; Hayashi, T.; Oki, T. Org. Lett. 2012, 14, 1054-1057.

42. Huang, D.; Wang, H.; Xue, F.; Guan, H.; Li, L.; Peng, X.; Shi, Y. Org. Lett. 2011, 13, 6350-6353.

43. Denmark, S. E.; Burk, M. T. Org. Lett. 2011, 14, 256-259.

44. Hennecke, U.; Müller, C. H.; Fröhlich, R. Org. Lett. 2011, 13, 860-863.

45. Tay, D. W.; Leung, G. Y. C.; Yeung, Y.-Y. Angew. Chem., Int. Ed. 2014, 53, 5161-5164.

46. Zeng, X.; Miao, C.; Wang, S.; Xia, C.; Sun, W. Chem. Commun. 2013, 2418-2420. 47. Kang, B.; Mowat, J.; Pinter, T.; Britton, R. Org. Lett. 2009, 11, 1717-1720.

48. Kang, B.; Chang, S.; Decker, S.; Britton, R. Org. Lett. 2010, 12, 1716-1719. 49. Holmes, M. T.; Britton, R. Chem.-Eur. J. 2013, 19, 12649-12652.

50. Chang, S.; Hur, S.; Britton, R. Angew. Chem., Int. Ed. 2015, 54, 211-214.

51. Keshipeddy, S.; Martınez, I.; Castillo, B. F.; Morton, M. D.; Howell, A. R. J. Org. Chem. 2012, 77, 7883-7890.

52. Fuwa, H.; Ishigai, K.; Hashizume, K.; Sasaki, M. J. Am. Chem. Soc. 2012, 134, 11984-11987.

53. Umezawa, T.; Oguri, Y.; Matsuura, H.; Yamazaki, S.; Suzuki, M.; Yoshimura, E.; Furuta, T.; Nogata, Y.; Serisawa, Y.; Matsuyama-Serisawa, K.; Abe, T.; Matsuda, F.: Suzuki, M.; Okino, T. Angew. Chem., Int. Ed. 2014, 53, 3909-3912.

54. Braddock, D. C.; Bhuva, R.; Millan, D. S.; Pérez-Fuertes, Y.; Roberts, C. A.; Sheppard, R. N.; Solanki, S.; Stokes, E. S. E.; White, A. J. P. Org. Lett. 2007, 9, 445-448.

55. Willwacher, J.; Fürstner, A. Angew. Chem., Int. Ed. 2014, 53, 4217-4221.

56. Guo, S.; Liu, J.; Ma, D. Angew. Chem., Int. Ed. 2015, 54, 1298-1301.

57. Mohapatra, D. K.; Naidu, P. R.; Reddy, D. S.; Nayak, S.; Mohapatra, S. Eur. J. Org. Chem. 2010, 2010, 6263-6268.

58. Trost, B. M. Tetrahedron 1977, 33, 2615-2649.

59. Trost, B. M.; Van Vranken, D. L. Chem. Rev. 1996, 96, 395-422.

60. He, A.; Sutivisedsak, N.; Spilling, C. D. Org. Lett. 2009, 11, 3124-3127.

61. Olszewska, B.; Szulc, I.; Kryczka, B.; Kubiak, A.; Porwański, S.; Zawisza, A. Tetrahedron: Asymmetry 2013, 24, 212-216.

62. Roulland, E. Angew. Chem., Int. Ed. 2008, 47, 3762-3765.

63. Arthuis, M.; Beaud, R.; Gandon, V.; Roulland, E. Angew. Chem., Int. Ed. 2012, 51, 10510-10514.

64. Brovetto, M.; Seoane, G. J. Org. Chem. 2008, 73, 5776-5785.

65. Roy, S.; Spilling, C. D. Org. Lett. 2010, 12, 5326-5329.

66. Roy, S.; Spilling, C. D. Org. Lett. 2012, 14, 2230-2233.

67. Nesbitt, C. L.; McErlean, C. S. P. Tetrahedron Lett. 2009, 50, 6318-6320.

68. Semmelhack, M. F.; Kim, C.; Zhang, N.; Bodurow, C.; Sanner, M.; Dobler, W.; Meier, M. Pure Appl. Chem. 1990, 62.

69. Markovič, M.; Lopatka, P.; Koóš, P.; Gracza, T. Synthesis 2014, 46, 817-821.

70. Valli, M.; Bruno, P.; Sbarbada, D.; Porta, A.; Vidari, G.; Zanoni, G. J. Org. Chem. 2013, 78, 5556-5567.

71. Trost, B. M.; Rey, J. Org. Lett. 2012, 14, 5632-5635.

72. Huang, X.; Song, L.; Xu, J.; Zhu, G.; Liu, B. Angew. Chem., Int. Ed. 2013, 52, 952-955.

73. Minuti, L.; Barattucci, A.; Bonaccorsi, P. M.; Di Gioia, M. L.; Leggio, A.; Siciliano, C.; Temperini, A. Org. Lett. 2013, 15, 3906-3909.

74. Loy, R. N.; Jacobsen, E. N. J. Am. Chem. Soc. 2009, 131, 2786-2787.

75. Mitchell, T. A.; Romo, D. J. Org. Chem. 2007, 72, 9053-9059.

76. Mitchell, T. A.; Zhao, C.; Romo, D. J. Org. Chem. 2008, 73, 9544-9551.

77. Mitchell, T. A.; Zhao, C.; Romo, D. Angew. Chem., Int. Ed. 2008, 47, 5026-5029.

78. Zheng, T.; Narayan, R. S.; Schomaker, J. M.; Borhan, B. J. Am. Chem. Soc. 2005, 127, 6946-6947.

79. Narayan, R. S.; Borhan, B. J. Org. Chem. 2006, 71, 1416-1429.

80. Fang, B.; Xie, X.; Li, H.; Jing, P.; Gu, J.; She, X. Tetrahedron Lett. 2013, 54, 6349-6351.

81. de La Torre, A.; Lee, Y. Y.; Oger, C.; Sangild, P. T.; Durand, T.; Lee, J. C.-Y.; Galano, J.-M. Angew. Chem., Int. Ed. 2014, 53, 6249-6252.

82. de la Torre, A.; Lee, Y. Y.; Mazzoni, A.; Guy, A.; Bultel-Poncé, V.; Durand, T.; Oger, C.; Lee, J. C.-Y.; Galano, J.-M. Chem.-Eur. J. 2015, 21, 2442-2446.

83. Unsworth, W. P.; Clark, N.; Ronson, T. O.; Stevens, K.; Thompson, A. L.; Lamont, S. G.; Robertson, J. Chem. Commun. 2014, 11393-11396.

84. Aricò, F.; Tundo, P.; Maranzana, A.; Tonachini, G. ChemSusChem 2012, 5 , 1578-1586.

85. Rye, C.; Barker, D. Synlett 2009, 3315-3319.

86. Deng, L.-S.; Huang, X.-P.; Zhao, G. J. Org. Chem. 2006, 71, 4625-4635.

87. Reddy, K. M.; Yamini, V.; Singarapu, K. K.; Ghosh, S. Org. Lett. 2014, 16, 2658-2660.

88. Secci, F.; Frongia, A.; Rubanu, M. G.; Sechi, M. L.; Sarais, G.; Arca, M.; Piras, P. P. Eur. J. Org. Chem. 2014, 2014, 6659-6675.

89. Pihko, P. M.; Aho, J. E. Org. Lett. 2004, 6, 3849-3852.

90. Martinková, M.; Mezeiová, E.; Fabišíková, M.; Gonda, J.; Pilátová, M.; Mojžiš, J. Carbohydr. Res. 2015, 402, 6-24.

91. Pandey, G.; Luckorse, S.; Budakoti, A.; Puranik, V. G. Tetrahedron Lett. 2010, 51, 2975-2978.

92. Baldwin, J. E. J. Chem. Soc., Chem. Commun. 1976, 734-736. 
93. Kelly, B. D.; Allen, J. M.; Tundel, R. E.; Lambert, T. H. Org. Lett. 2009, 11, $1381-1383$

94. Brown, T. J.; Weber, D.; Gagné, M. R.; Widenhoefer, R. A. J. Am. Chem. Soc. 2012 134, 9134-9137.

95. Zhang, Z.; Liu, C.; Kinder, R. E.; Han, X.; Qian, H.; Widenhoefer, R. A. J. Am. Chem. Soc. 2006, 128, 9066-9073.

96. Alcaide, B.; Almendros, P.; Martínez del Campo, T. Angew. Chem., Int. Ed. 2007, 46, 6684-6687.

97. Trost, B. M.; Gutierrez, A. C.; Livingston, R. C. Org. Lett. 2009, 11, 2539-2542.

98. Jimmidi, R.; Guduru, S. K. R.; Arya, P. Org. Lett. 2015, 17, 468-471.

99. Valot, G.; Regens, C. S.; O'Malley, D. P.; Godineau, E.; Takikawa, H.; Fürstner, A. Angew. Chem., Int. Ed. 2013, 52, 9534-9538.

100. Valot, G.; Mailhol, D.; Regens, C. S.; O’Malley, D. P.; Godineau, E.; Takikawa, H.; Philipps, P.; Fürstner, A. Chem.-Eur. J. 2015, 21, 2398-2408.

101. Wu, D.; Forsyth, C. J. Org. Lett. 2013, 15, 1178-1181.

102. Hayakawa, I.; Ueda, M.; Yamaura, M.; Ikeda, Y.; Suzuki, Y.; Yoshizato, K.; Kigoshi, H. Org. Lett. 2008, 10, 1859-1862.

103. He, C.; Zhu, C.; Wang, B.; Ding, H. Chem.-Eur. J. 2014, 20, 15053-15060.

104. Bai, W.-J.; Green, J. C.; Pettus, T. R. R. J. Org. Chem. 2012, 77, 379-387.

105. Ward, A. F.; Wolfe, J. P. Org. Lett. 2009, 11, 2209-2212.

106. Nicolai, S.; Sedigh-Zadeh, R.; Waser, J. J. Org. Chem. 2013, 78, 3783-3801.

107. Nicolai, S.; Waser, J. Org. Lett. 2011, 13, 6324-6327.

108. Klein, E.; Rojahn, W. Tetrahedron 1965, 21, 2353-2358.

109. Baldwin, J. E.; Crossley, M. J.; Lehtonen, E.-M. M. J. Chem. Soc., Chem. Commun. 1979, 918-920.

110. Piccialli, V. Synthesis 2007, 2007, 2585-2607.

111. Sheikh, N. S. Org. Biomol. Chem. 2014, 12, 9492-9504.

112. Pilgrim, B. S.; Donohoe, T. J. J. Org. Chem. 2013, 78, 2149-2167.

113. Takenaka, K.; Dhage, Y. D.; Sasai, H. Chem. Commun. 2013, 11224-11226.

114. Desai, L. V.; Sanford, M. S. Angew. Chem. Int. Ed. 2007, 46, 5737-5740.

115. Donohoe, T. J.; Harris, R. M.; Williams, O.; Hargaden, G. C.; Burrows, J.; Parker, J. J. Am. Chem. Soc. 2009, 131, 12854-12861.

116. Donohoe, T. J.; Winship, P. C. M.; Tatton, M. R.; Szeto, P. Angew. Chem., Int. Ed. 2011, 50, 7604-7606

117. Donohoe, T. J.; Lipiński, R. M. Angew. Chem., Int. Ed. 2013, 52, 2491-2494.

118. Brown, L. J.; Spurr, I. B.; Kemp, S. C.; Camp, N. P.; Gibson, K. R.; Brown, R. C. D. Org. Lett. 2008, 10, 2489-2492.

119. Morris, C. L.; Hu, Y.; Head, G. D.; Brown, L. J.; Whittingham, W. G.; Brown, R. C. D. J. Org. Chem. 2009, 74, 981-988.

120. Al Hazmi, A. M.; Sheikh, N. S.; Bataille, C. J. R.; Al-Hadedi, A. A. M.; Watkin, S. V.: Luker, T. J.; Camp, N. P.; Brown, R. C. D. Org. Lett. 2014, 16, 5104-5107.

121. Daub, M. E.; Prudhomme, J.; Le Roch, K.; Vanderwal, C. D. J. Am. Chem. Soc. 2015, 137, 4912-4915.

122. Celindro, N. C.; Kim, T. W.; Kang, S. H. Chem. Commun. 2012, 6295-6297.

123. Dias, L. C.; Ferreira, M. A. B. J. Org. Chem. 2012, 77, 4046-4062.

124. Fries, P.; Halter, D.; Kleinschek, A.; Hartung, J. J. Am. Chem. Soc. 2011, 133, 3906-3912.

125. Miller, Y.; Miao, L.; Hosseini, A. S.; Chemler, S. R. J. Am. Chem. Soc. 2012, 134, 12149-12156.

126. Thompson, S. J.; Thach, D. Q.; Dong, G. J. Am. Chem. Soc. 2015, 137, $11586-11589$

127. Xie, Y.; Floreancig, P. E. Angew. Chem., Int. Ed. 2014, 53, 4926-4929.

128. Fehr, C.; Magpantay, I.; Saudan, L.; Sommer, H. Eur. J. Org. Chem. 2010, 2010, 6153-6156.

129. Albertson, A. K. F.; Lumb, J.-P. Angew. Chem., Int. Ed. 2015, 54, 2204-2208.

130. Marinetti, A.; Jullien, H.; Voituriez, A. Chem. Soc. Rev. 2012, 41, 4884-4908.

131. Evans, P. A.; Inglesby, P. A. J. Am. Chem. Soc. 2012, 134, 3635-3638.

132. Körber, N.; Rominger, F.; Müller, T. Synlett 2010, 782-786.

133. Meng, T.; Hu, Y.; Zhao, Q.; Yu, T.; Wang, S. Tetrahedron 2011, 67, 8710-8716.

134. Mukherjee, S.; Roy, R.; Chandra Roy, S. Eur. J. Org. Chem. 2014, 2014, 2980-2985.

135. Xu, L.; Huang, X. Tetrahedron Lett. 2008, 49, 500-503.

136. Esteves, A. P.; Ferreira, E. C.; Medeiros, M. J. Tetrahedron 2007, 63, 3006-3009.

137. Chemla, F.; Dulong, F.; Ferreira, F.; Nüllen, M.; Pérez-Luna, A. Synthesis 2011, 2011, 1347-1360.

138. Kuo, J. L.; Hartung, J.; Han, A.; Norton, J. R. J. Am. Chem. Soc. 2015, 137, 1036-1039.

139. Zhu, H.; Leung, J. C. T.; Sammis, G. M. J. Org. Chem. 2015, 80, 965-979.

140. Kim, C. H.; An, H. J.; Shin, W. K.; Yu, W.; Woo, S. K.; Jung, S. K.; Lee, E. Angew. Chem., Int. Ed. 2006, 45, 8019-8021.

141. Ko, H. M.; Lee, C. W.; Kwon, H. K.; Chung, H. S.; Choi, S. Y.; Chung, Y. K.; Lee, E. Angew. Chem., Int. Ed. 2009, 48, 2364-2366.

142. Toumieux, S.; Beniazza, R.; Desvergnes, V.; Aráoz, R.; Molgó, J.; Landais, Y. Org. Biomol. Chem. 2011, 9, 3726-3732.

143. Donner, C. D. Org. Lett. 2013, 15, 1258-1261.

144. Jervis, P. J.; Kariuki, B. M.; Cox, L. R. Tetrahedron Lett. 2008, 49, 2514-2518.

145. Braun, M.; Richrath, B. Synlett 2009, 968-972.

146. Reddy, A. R.; Zhou, C.-Y.; Guo, Z.; Wei, J.; Che, C.-M. Angew. Chem., Int. Ed. 2014, $53,14175-14180$

147. Gibeau, A. L.; Snyder, J. K. Org. Lett. 2011, 13, 4280-4283.

148. Nasveschuk, C. G.; Rovis, T. J. Org. Chem. 2008, 73, 612-617.

149. Friestad, G. K.; Lee, H. J. Org. Lett. 2009, 11, 3958-3961.

150. Aljarilla, A.; Plumet, J. Synthesis 2008, 2008, 3516-3524.

151. Benjamin, N. M.; Martin, S. F. Org. Lett. 2011, 13, 450-453.

152. Gharpure, S. J.; Reddy, S. R. B. Tetrahedron Lett. 2010, 51, 6093-6097.
153. Pan, S.; Xuan, J.; Gao, B.; Zhu, A.; Ding, H. Angew. Chem., Int. Ed. 2015, 54, 6905-6908

154. Ying, J.; Pu, L. Chem.-Eur. J. 2014, 20, 16301-16307.

155. Escavabaja, P.; Viala, J.; Coquerel, Y.; Rodriguez, J. Adv. Synth. Catal. 2012, 354 3200-3204.

156. Zhang, W.-B.; Lin, G.; Shao, W.-B.; Gong, J.-X.; Yang, Z. Chem.-Asian J. 2015, 10 903-909.

157. Zhang, W.; Shao, W.; Li, F.; Gong, J.; Yang, Z. Chem.-Asian J. 2015, 10, $1874-1880$

158. Lu, P.; Gu, Z.; Zakarian, A. J. Am. Chem. Soc. 2013, 135, 14552-14555.

159. Campbell, M. J.; Johnson, J. S.; Parsons, A. T.; Pohlhaus, P. D.; Sanders, S. D. J Org. Chem. 2010, 75, 6317-6325.

160. Smith, A. G.; Slade, M. C.; Johnson, J. S. Org. Lett. 2011, 13, 1996-1999.

161. Benfatti, F.; de Nanteuil, F.; Waser, J. Org. Lett. 2012, 14, 386-389.

162. Christie, S. D. R.; Cummins, J.; Elsegood, M. R. J.; Dawson, G. Synlett 2009 $257-259$.

163. Parsons, A. T.; Campbell, M. J.; Johnson, J. S. Org. Lett. 2008, 10, 2541-2544.

164. Mei, L.; Wei, Y.; Xu, Q.; Shi, M. Organometallics 2013, 32, 3544-3556.

165. Parsons, A. T.; Johnson, J. S. J. Am. Chem. Soc. 2009, 131, 3122-3123.

166. Benfatti, F.; de Nanteuil, F.; Waser, J. Chem.-Eur. J. 2012, 18, 4844-4849.

167. de Nanteuil, F.; Serrano, E.; Perrotta, D.; Waser, J. J. Am. Chem. Soc. 2014, 136, 6239-6242.

168. Yang, G.; Shen, Y.; Li, K.; Sun, Y.; Hua, Y. J. Org. Chem. 2011, 76, 229-233.

169. Yang, G.; Sun, Y.; Shen, Y.; Chai, Z.; Zhou, S.; Chu, J.; Chai, J. J. Org. Chem. 2013, 78, 5393-5400.

170. Dunn, J.; Motevalli, M.; Dobbs, A. P. Tetrahedron Lett. 2011, 52, 6974-6977.

171. Dobbs, A. P.: Dunn, J. Tetrahedron Lett. 2012, 53, 2392-2395.

172. Lu, J.-M.; Shi, M. J. Org. Chem. 2008, 73, 2206-2210.

173. Su, C.; Liu, Q.; Ni, Y.; Huang, X. Tetrahedron Lett. 2009, 50, 4381-4383.

174. Su, C.; Huang, X.; Liu, O.; Huang, X. J. Org. Chem. 2009, 74, 8272-8279.

175. Yamazaki, S. Chem.-Eur. J. 2008, 14, 6026-6036.

176. Morikawa, S.; Yamazaki, S.; Furusaki, Y.; Amano, N.; Zenke, K.; Kakiuchi, K. J. Org. Chem. 2006, 71, 3540-3544.

177. Morikawa, S. Yamazaki, S. Tsukada, M. Izuhara, S. Morimoto, T· Kakiuchi, K. J. Org. Chem. 2007, 72, 6459-6463.

178. Pedduri, Y.; Williamson, J. S. Tetrahedron Lett. 2008, 49, 6009-6012.

179. Jahn, U.: Rudakov, D.: Jones, P. G. Tetrahedron 2012, 68, 1521-1539.

180. Grandjean, J.-M. M.; Nicewicz, D. A. Angew. Chem., Int. Ed. 2013, 52 3967-3971.

181. Zhang, C.; Lu, X. J. Org. Chem. 1995, 60, 2906-2908.

182. Xu, S.; Zhou, L.; Ma, R.; Song, H.; He, Z. Chem-Eur. J. 2009, 15, 8698-8702.

183. Angle, S. R.; Choi, I. Tetrahedron Lett. 2008, 49, 6245-6249.

184. Borg, T.; Timmer, B.; Somfai, P. Tetrahedron Lett. 2013, 54, 3916-3918.

185. Bates, R. H.; Shotwell, J. B.; Roush, W. R. Org Lett. 2008, 10, 4343-4346.

186. Ramachandran, P. V.; Nair, H. N. G.; Gagare, P. D. J. Org. Chem. 2012, 77 5394-5398.

187. Xu, X.; Han, X.; Yang, L.; Hu, W. Chem.-Eur. J. 2009, 15, 12604-12607.

188. Jing, C.: Xing, D: Gao, L. Li, J.: Hu, W. Chem-Eur. J. 2015, 21, 19202-19207.

189. Urabe, F.; Miyamoto, S.; Takahashi, K.; Ishihara, J.; Hatakeyama, S. Org. Lett. 2014, 16, 1004-1007.

190. Faustino, H.; Alonso, I.; Mascareñas, J. L.; López, F. Angew. Chem., Int. Ed. 2013 52, 6526-6530.

191. Pan, J.; Zhang, W.; Zhang, J.; Lu, S. Tetrahedron Lett. 2007, 48, 2781-2785.

192. Lange, J.; Schaumann, E. Eur. J. Org. Chem. 2009, 2009, 4674-4684.

193. Sugimura, H.; Sato, S.; Tokudome, K.; Yamada, T. Org. Lett. 2014, 16, 3384-3387.

194. Lee, J.; Panek, J. S. J. Org. Chem. 2015, 80, 2959-2971.

195. Kim, S.-H.; Oh, S.-J.; Ho, P.-S.; Kang, S.-C.; O, K.-J.; Yu, C.-M. Org. Lett. 2008, 10, 265-268.

196. Chavre, S. N.; Choo, H.; Lee, J. K.; Pae, A. N.; Kim, Y.; Cho, Y. S. J. Org. Chem 2008, 73, 7467-7471.

197. Spivey, A. C.; Laraia, L.; Bayly, A. R.; Rzepa, H. S.; White, A. J. P. Org. Lett. 2010 12, 900-903.

198. Reddy, B.; Anjum, S.; Reddy, G.; Rao, T. Synlett 2011, 2951-2954.

199. DeAngelis, A.: Taylor, M. T.; Fox, J. M. J. Am. Chem. Soc. 2009, 131, 1101-1105.

200. Hashimoto, Y.; Itoh, K.; Kakehi, A.; Shiro, M.; Suga, H. J. Org. Chem. 2013, 78 6182-6195.

201. Roux, M.; Aouf, C.; Parrain, J.-L.; Santelli, M. Tetrahedron Lett. 2007, 48 $4011-4014$

202. Malkov, A. V.; Kysilka, O.; Edgar, M.; Kadlčíková, A.; Kotora, M.; Kočovský, P. Chem.-Eur. J. 2011, 17, 7162-7166.

203. Zhang, Z.; Ding, Y.; Xu, J.; Chen, Y.; Forsyth, C. J. Org. Lett. 2013, 15 , $2338-2341$.

204. Li, L.; Ye, X.; Wu, Y.; Gao, L.; Song, Z.; Yin, Z.; Xu, Y. Org. Lett. 2013, 15 , 1068-1071.

205. Tsuna, K.; Noguchi, N.; Nakada, M. Chem.-Eur. J. 2013, 19, 5476-5486.

206. Fujiwara, K.; Suzuki, Y.; Koseki, N.; Aki, Y.; Kikuchi, Y.; Murata, S.; Yamamoto, F.; Kawamura, M.; Norikura, T.; Matsue, H.; Murai, A.; Katoono, R.; Kawai, H.; Suzuki, T. Angew. Chem., Int. Ed. 2014, 53, 780-784.

207. Trost, B. M.; Bringley, D. A.; Silverman, S. M. J. Am. Chem. Soc. 2011, 133 7664-7667.

208. Trost, B. M.; Bringley, D. A. Angew. Chem., Int. Ed. 2013, 52, 4466-4469.

209. Brandt, A.; Wojtasiewicz, A.; Śnieżek, M.; Mạkosza, M. Tetrahedron 2010, 66 3378-3385.

210. Komsta, Z.; Barbasiewicz, M.; Mąkosza, M. J. Org. Chem. 2010, 75, 3251-3259. 


\section{Biographical sketch}

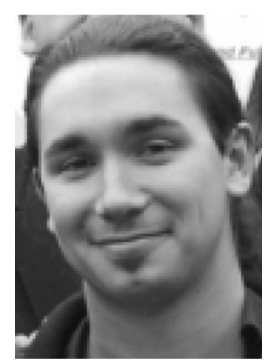

Aurélien de la Torre was born in 1988 in Montpellier, France. He graduated in Chemical Engineering from the Ecole Nationale Supérieure de Chimie de Montpellier and obtained a research M.Sc. Degree in organic chemistry from the University of Montpellie II in 2011. In 2014, he received his PhD from the University of Montpellier I, under the supervision of Dr. Jean-Marie Galano and Dr. Camille Oger, working on the total synthesis of isofuranoid compounds. Since 2015, he is undertaking a post-doctoral research in the group of Prof. Nuno Maulide in the University of Vienna, Austria.

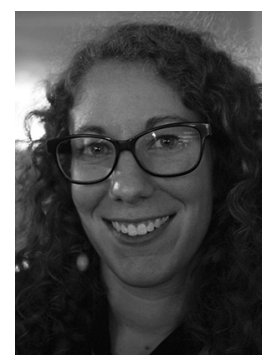

Claire Cuyamendous was born in Orléans (France) in 1987. She studied organic chemistry at the National Graduate School of Chemistry of Montpellier (France), where she received her graduation and master degree in 2012. In 2015, she obtained her PhD at the University of Montpellier in the field of total synthesis of phytofurans, under the supervision of Dr. Camille Oger and Dr. Jean-Marie Galano. Currently she is a postdoctoral fellow at the center for biodiscovery in Victoria University of Wellington. She works with Dr. Joanne Harvey and Dr. Paul Teesdale-Spittle on the total synthesis of Pateamine.

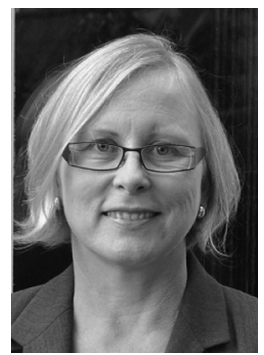

Valérie Bultel-Poncé was born in Montpellier and received her undergraduate education at Montpellier University. She obtained her Ph.D in 1991 at Perpignan University and she did postdoctoral studies at Muséum National d'Histoire Naturelle in Paris, in the field of natural products chemistry. At present she is an engineer at Montpellier University. Her research interests are in the areas of organic synthesis, medicinal chemistry, particularly on total synthesis of oxygenated derivatives obtained in vivo from non-enzymatic peroxidation of PUFAs, like isoprostanes, neuroprostanes...

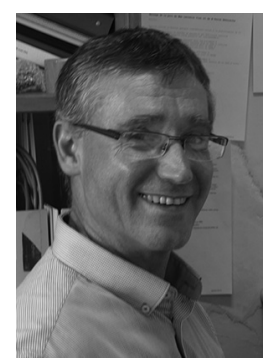

Thierry Durand studied chemistry at University of Paris VI, and then moved to Montpellier and received his PhD degree at University of Montpellier I in 1990. After a postdoctoral training at Florida Institute of Technology in Melbourne, USA, with Joshua Rokach, he became Chargé de Recherche CNRS at the University of Montpellier I in 1991. He finished his Habilitation in 1996 and became Directeur de Recherche CNRS in 2002. He is a group leader at the Institute of Biomolécules Max Mousseron. His research interests include the total synthesis of oxygenated cyclic and non cyclic metabolites of polyunsaturated fatty acids, mainly leukotrienes, iso-, phyto- and neuroprostanes, as well as dihydroxylated PUFAs and more recently lipophenols and the understanding of the role of such bioactive lipids and lipophenols by developing collaborations with chemists, biochemists, biologists and clinicians across the world.

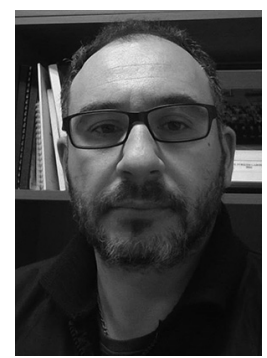

Jean-Marie Galano studied chemistry at Paul Cézanne Université Marseille and obtained his PhD under the supervision of Honoré Monti in 2001. He then moved to the University of Oxford to pursue a postdoctoral fellowship with David H. Hodgson on the development of new methods for the total synthesis of natural products. In October 2005, he joined the CNRS as a Chargé de Recherche at Université of Montpellier. His research focuses on the total synthesis and discovery of new lipid metabolites, and to discover their potential implications in human health.

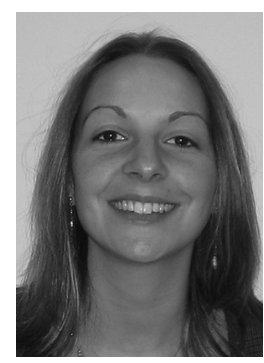

Camille Oger was born in Saint-Gaudens (France) in 1984. She studied chemistry at Paul Sabatier University in Toulouse and University of Paris VI. She then moved to Montpellier and received her $\mathrm{PhD}$ in the field of total synthesis of neuroprostanes at the University of Montpellier II, in 2010. She did a post doctoral work with Pr. Ilan Marek at the Technion -Israel Institute of Technology and was promoted to assistant professor at the University of Montpellier in 2011. Her research interests include the development of new strategies toward the synthesis of bioactive lipids. 